\title{
$666.972 .0917=6068-12$ \\ el cloruro cálcico como acelerador en la prefabricación del hormigón
}

\author{
J. CALLEJA CARRETE \\ Doctor en Ciencias Guimicas
}

\section{INTRODUCCION}

\section{t.I. La aceleración del fraguado $y$ en- durecimiento de los aglomerantes hidráulicos.}

El problema de acelerar el fraguado y endureclmiento de los aglomerantes hidráulicos $y$, en particular, del cemento portland, es muy antiguo. Se ha tratado de resolver $y$, de hecho, resuelto en muchos casos, por los medios más diversos, desde los puramente físicos a los puramente químicos.

Entre los primeros destaca, con carácter exclusivo, la aplicación de calor en las más variadas formas, según la naturaleza y el tipo de trabajo a realizar, de lo cual existen ya hasta el año 1951 , abundantes referencias bibliográficas (20). El más elemental de los procedimlentos de aplicar calor ha sido y es el de calentar previamente los áridos del hormigón o mortero y el agua de amasado (21), antes de efectuar la mezcla de estos materiales. Suele tener mayor aplicación en la confección de hormigón en masa.

Otro medio de acelerar el fraguado y endurecimiento, más aplicable a plezas prefabricadas en taller, consiste en someter éstas a un tratamiento con vapor, bien libre o bien a presión, en autoclaves. Dentro de la industria de prefabricación en hormlgón ordinarlo, así como en las de hormigones especiales, el método está considerableménte extendido en todo el mundo.

En menor cuantía se ha aplicado el tratamiento térmico mediante agua caliente, sumer- giendo en ella las piezas o elementos constructivos.

No faltan tampoco ejemplos en que, en grandes estructuras de hormigón en masa, $y$ partićularmente en climas y regiones con temperaturas muy bajas, se ha aplicado la calefacción eléctrica por efecto joule, de manera especial donde y cuando la energía eléctrica está disponible $y$ es barata.

Salvo el factor económico en cada caso, técnicamente debe ser posible, en determinadas circunstancias, la aplicación de calor al hormigón por diatermia, rayos infrarrojos, etc.

Los métodos quimlcos de acelerar el fraguado y endurecimiento se fundan en los efectos causados por determinadas adiciones, $y$ en las' dosis más adecuadas, generalmente añadidas al agua de amasado en el momento de proceder a tal operación. Sin que esto excluya la posibilidad de que el aglomerante ya contenga de por sí, dosificado y mezclado en forma sólida y pulverulenta, el agente acelerador. Recientemente se ha propuesto un método de activar el endurecimiento por adición de gérmenes cristalinos de cemento hidratado, los cuales actúan como catalizadores (29).

Entre las adiclones de tipo químico más conocidas y empleadas para los fines expuestos figura el cloruro cálcico (19).

No faltan los procedimientos mixtos, fisicos y químicos, de lograr la aceleración del endurecimiento, los cuales consisten, en general, en combinar el efecto del calor con el de una adición de naturaleza química. El cloruro cálcico se presta bien a ello, ya que su acción se suma a la de la temperatura, sin que ambas se 
estorben mutuamente (10). Incluso los métodos químicos combinados (adición de gérmenes cristalinos de cemento hidratado y cloruro cálcico) dan a veces buenos resultados ${ }^{(29)}$, como también, posiblemente, las mezclas de cloruros (10) (44) (51) (75) (98) y cloruros y sulfatos (14).

\subsection{Los problemas de la prefabricación}

En la industria de-piezas y elementos prefabricados de mortero u hormigón es preciso confeccionar, de análogo modo a como sucede en la industria ladrillera, por ejemplo, un elevado número de piezas al día.

Comoquiera que éstas han de ser moldeadas, ello representa la necesidad de disponer de una gran cantidad de moldes, sólo reducible si se consigue acortar el tiempo de permanencia de la pieza dentro de cada uno.

Por otra parte, las piezas requieren tener para su manipulación $y$, más aứn, para su puesta en servicio, unas condiciones mecánico-resistentes minimas, que adquieren gracias a un proceso de curado en el que juega el factor tiempo.

El curado de un gran número de plezas durante el tiempo mínimo necesario para que se efectúe en las debidas condiciones, requiere también espacio.

El factor tiempo influye, a su vez, en el coste de la mano de obra y en la productividad.

Por consiguiente, toda acción que tienda a acelerar el fraguado y el endurecimiento acortará el tiempo de permanencia de las plezas en los moldes, reducirá el número de los necesarios. abreviará el curado, anticipará la puesta en servicio $y$, en definitiva, incrementará la produc. tividad, disminuyendo el volumen de la mano de obra.

Los métodos físicos antes comentados se aplican con profusión, pero exigen equipos de

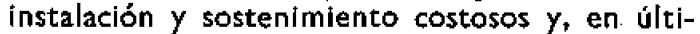
mo extremo, no desdeñan en ningún caso la ayuda complementaria, muy destacada a veces. que les prestan los métodos químicos. Exigen, además, una estrecha vigilancia por lo que respecta a la marcha de los períodos de calefacción y enfriamiento, clave del éxito en todos los casos. No basta conseguir buenas resistencias a corta edad, sino que es preciso que, además, las resistencias a los plazos normales y a largos plazos no se vean disminuidas o, a lo más, disminuyan en insignificante $y$ no peligrosa proporción.

Todo esto quiere decir que los métodos químicos, de control riguroso más fácil, bien por sí solos, o bien como complemento notable y eficaz de los físicos, tienen una gran importancia en todo problema de prefabricación, si bien, a veces por sí solos no parecen permitír llegar a una solución completa (10).

Entre los métodos químicos, alcanza un grandísimo interés el basado en el empleo del cloruro cálcico como acelerador del fraguado y endurecimiento del cemento portland.

En prefabricación de hormigón se producen piezas y elementos de los más variados cipos. Entre aquéllos han cobrado importancia recientemente en muchos países los marcos de ventanas, de los que se trata más adelante, habiéndose reconocido que, en general, resultan más económaicos que los de madera, si se organiza racionalmente el plan de trabajo para su confección (47) (56) (87)

\subsection{Empleo del cloruro cálcico como ace- lerador del curado}

Datan de antiguo (1900) y son muy numerosos los trabajos de investigación y los ensayos y experiencias llevados a cabo en la práctica, relativos a la utilización del cloruro cálcico comercial, como agente acelerador de los procesos de fraguado y endurecimiento de los aglomerantes hidráulicos $\mathrm{y}$, en particular, del cemento portland.

Dentro del cuadro de las adiciones de naturaleza química empleadas con el mismo o parecido fin, el cloruro cálcico es tal vez la más universalmente conocida y empleada (1) (34). Es también una de las más discutidas en cuanto a su acción, hasta el punto de que, en algunos aspectos, las opiniones y conclusiones de los distintos investigadores están en franca oposición.

La bibliografia sobre el tema es muy abundante (II)*. En el aspecto general, el cloruro cálcico contribuye al desarrollo de altas resistencias iniciales, al acelerar, en determinadas do-

* Rectentamenta ha putlicado aste Instituto un Manual titulado aEmpleo del Cloruro eálcico en Conscruccións (IS). 
sis, los procesos normales de fraguado y endurecimiento. Es éste el efecto más destacado y generalmente aceptado de todos cuantos se atribuyen a su empleo, $y$ en tal sentido se pronuncian las conclusiones de los trabajos de Abrams (1), Rapp (86), Kalousek (45), Newman (73) y Shideler (95) (96), entre otros (21) (68),

Respecto de la influencia del cloruro cálcico en el tiempo de fraguado, se sabe que determinadas dosis, variables según otras circunstancias, lo acortan (12) (52) (63) (74) (79) (86) (88) (89) (90), mientras que cantidades mayores o menores que las correspondientes a dichas dosis lo alargan (7) (12) (18) (19) (28) (32) (52) (63) (90) (105). Las variaciones producidas por el cloruro cálcico en el principio y en el final del fraguado son análogas (49).

Entre los distintos investigadores han sido estudiadas las más diversas dosis del producto: hasta $4 \%(6)(04)(92)(100)(114), 5 \%{ }^{(40)}(79), 6 \%{ }^{(60)}$ (67) (91), $7,5 \%^{(104)}, 10 \%{ }^{(102)}, 16 \%{ }^{(52)}$ y $20 \%{ }^{(10)}$.

En cuanto al valor óptimo, es variable según el aspecto que se considere y según las condiciones experimentales, dentro de un mismo aspecto. Así, por ejemplo, desde el punto de vista general, la dosis óptima más comunmente aceptada es la de $2 \%$; en lo que concierne a las resistencias mecánicas, depende de si se consideran preferentemente las correspondientes a edades tempranas o a las de edades más avanzadas. Se han fijado como óptimas o, cuando menos, mejores que la no adicjón, aparte de la citada del $2 \%$ (48) ( $(4)$, las dosis de 2 a $3 \%$ (108), del $3 \%(84)(95)(108)(109)$, del $4 \%(80)(85)(92)(100)(108)$ (114) y del $5 \%(10)(61)$.

Algunos autores señalan, a partir de ciertos porcentajes, resistencias más bajas que las logradas sin adición de cloruro cálcico; estos porcentajes son igualmente variables, según las condiciones: $4 \%$ (1) (108), $5 \%$ (6) (94).

Todo esto. indica que, en todo caso, las resistencias mecánicas en función del porcentaje de cloruro cálcico adicionado pasan por un máximo, para valores variables de la adición, según las circunstancias (48).

No faltan opiniones acerca de que, si bien el cloruro cálcico en dosis adecuadas eleva las resistencias a la compresión, prácticamente siempre y a cualquier edad, las resistencias a la tracción, o bien se ven también aumentadas (102) (108), o bien se afectan poco (80) (81) (85).

Las condiciones de curado influyen notablemente, y así se ha comprobado que el cloruro cálcico, a temperaturas normales, produce me-
Jores efectos sobre probetas o piezas curadas al aire que sobre las curadas bajo agua o en atmósfera húmeda(i); incluso el curado al aire con cloruro cálcico da resultados análogos a los del curado en húmedo sin él(6). A esto puede ser tamblén debido el. hecho observado de que, a veces, las experiencias llevadas a cabo con cloruro cálcico en obra dan relativamente mejores resultados que las efectuadas en laboratorios(3).

Se ha escrito también bastante acerca de la posible acción química del cloruro cálcico sobre el cemento, justificativa de los efectos ya mencionados, así como de algunos otros.

Se sabe que en disolución saturada de $\mathrm{Ca}(\mathrm{OH})_{2}$ la velocidad de hidratación del cemento se halla considerablemente retardada. El retardo es menor en presencia de yeso, el cual activa la hidratación de los sillicatos cálei$\cos$ y contiene la de los aluminatos (40). Análogo papel desempeña el $\mathrm{CaCl}_{2}$ (111), el cual rebaja el valor del $\mathrm{pH}^{(33)}$, con lo cual los silicatos se disuelven más deprisa, aumentando la concentración de iones calcio en la disolución y contribuyendo así a la más rápida formación de la disolución sobresaturada preclsa para la precipitación de los hidratos $y$ de los geles causantes de la trabazón del cemento.

Por la presencia del $\mathrm{CaCl}_{2}$ en grandes cantidades, el $\mathrm{pH}$ puede descender tanto que impida totalmente la precipitación de aluminato cálcico y se forme en su lugar $\mathrm{Al}(\mathrm{OH})_{s}{ }^{(40)(45)}$.

El $\mathrm{CaCl}_{2}$ difiere en su acción del $\mathrm{CaSO}_{4}$ en que aumenta la concentración de álcalis disueltos, lo que se creyó aceleraba la precipitación de sulfoaluminato cálcico ( $y$ también, tal vez, la de cloroaluminato cálcico), disminuyendo asi la concentración de $\mathrm{CaO}_{\text {y }} \mathrm{SO}_{3}$ en la disolución (8).

Existen bastantes posibilidades de que el $\mathrm{CaCl}_{2}$ forme cloroaluminato cálcico, análogo al sulfoal uminato (23) (50) (80) (93) (99) (107) (111) (113). En tal sentido, y por lo anteriormente expuesto, parece que la cantidad óptima de cloruro cálcico a recomendar como adición para un cemento portland determinado, debe estar probablemente limitada por la que químicamente pueda combinarse con los aluminatos, sin que quede sal en estado libre (véase apartado 3).

Es en el terreno de los cambios de volumen donde la acción del cloruro cálcico es más discutida $y$, de hecho, en algún trabajo se considera la cuestión como problemática (3). Un sector sustenta la idea de que los cambios de volumen son análogos, tanto empleando como sin em- 
plear cloruro cálcico (99) (100). Las opiniones distintas a ésta se encuadran a su vez, en tres grupos: para uno, el empleo del cloruro cálcico confiere al cemento una mayor constancia de volumen (49) (55) (80). Para otro, las expansiones y contracciones son considerablemente mayores con cloruro cálcico (37). Para el tercero, los cambios de volumen ocasionados por el uso del cloruro cálcico no son excesivos ni desfavorables en el caso de ambientes húmedos ${ }^{(3)}, 0$, dicho de otro modo, no son tales que aconsejen la proscripción del empleo del producto (29) (115).

Desde el punto de vista de la expansión, para algunos autores el cloruro cálcico en dosis de $1 \%$ aumenta la expansión Le Chatelier, y tanto menos cuanto mayor es la dosis (4B). Por otra parte, los aumentos de expansión no llegan a ser perjudiciales (96). Además, esta expansión ocasionada por el cloruro cálcico contrarresta la retracción natural que sólo se manifiesta a larga edad (39). Por último, no faltan opiniones en sentido contrario, según las cuales la máxima expansión observada con cloruro cálcico es menor que la máxima observada sin él (78), y ün cemento expansivo puede comportarse como no expansivo mediante adición de cloruro cálcico ${ }^{(67)}$.

Por lo que afecta a la retracción, diversos investigadores, manejando distintas dosis $y$. en condiciones experimentales variadas, concluyen que el cloruro cálcico produce un aumento de retracción (24) (57) (60) (61) (74) (92) (96) (97) (99) (100) (105) (106), mientras, por otro lado, otros sustentan la tesis contraria (23) (41) (42) (49)(78)(79) (80) (81) (82) (85) (106), - se muestran más eclécticos (100).

Los que apoyan la idea de que el cloruro cálcico disminuye, contrarresta, evita o previene la retracción, o atenúa el efecto de ésta, explican el hecho admitiendo una absorción y retención de la humedad por parte del producto (49) (65) (8I) (101), consecuencia de su higroscopicjdad (80) (82), la cual reduce las pérdidas de agua o tiende a reponerlas con rapidez (41) (80) (97)(99), evitando la formación de grietas, fisuras y roturas (2) (27) (80) (81). A ello contribuye también el hecho de que el cloruro cálcico acelera la hidratación, cristalización y endurecimiento (41) (99), con lo que se logra, por una parte, alcanzar la retracción total lo antes posible ${ }^{(99)} \gamma$, por otra, conseguir una resistencia que sea capaz de absorber y neutralizar las tensiones producidas por la retracción (13) (27) (81).

Otro aspecto importante a considerar en el empleo del cloruro cálçico es el de la corrosión de las armaduras, en el caso de hormigones y morteros armados y pretensados.

Sobre este particular las opiniones, si bien variadas, son más acordes, ya que, en general, se admite que el cloruro cálcico en las dosis ordinarias de $2 \%$ del producto comercial no produce efectos corrosivos en las armaduras, nocivos para el hormigón (29) (31) (66) (69) (70) (96) (106), o bien dichos efectos son muy ligeros $(7)$ y se presentan en las primeras edades (112), sin que tengan carácter progresivo (31) (74) (76) (103) (105) (112). Incluso dosis de cloruro cálcico comprendidas entre 0 y $10 \%$ no producen corrosión al cabo de un año(26) y más (72).

La corrosión observada a veces en las armaduras del hormigón confeccionado con cloruro cácico, es debida a espacios vacíos entre el metal y la masa del hormigón, que dejan a aquél fuera del contacto de éste (72) (77) (103). Estos espacios, debidos a falta de compacidad, se presentan preferentemente en hormigones amasados con grán cantidad de, agua (12) los cuales, por dicha razón, son porosos y permeables. En tales condiciones, ciertas partes de las armaduras son accesibles al oxígeno del aire y a la humedad (104) $y$, entonces, se produce la corrosión, tanto en presencia como en ausencia de cloruro cálcico (109) (112), si bien en el segundo caso es mayor. Por ello, en el caso del hormigón con cloruro cálcico es doblemente conveniente que la armadura esté bien embebida en la masa y que la adherencia sea inicialmente completa (31) (104) (112). A tal objeto son eficaces todos aquellos métodos y tratamientos que, sin aumentar la relación agua/cemento, permiten la obtención de hormigones más flúidos (16) (103). Las correspondientes adiciones para este fin no parecen ser incompatibles con el empleo del cloruro cálcico (30).

Casos especiales de corrosión de armaduras los constituyén aquéllos en que, con o sin cloruro cálcico, existen presentes en el hormigón otros cloruros, tales como el magnésico (104) (contenidos en los áridos), o cuando la corrosión obedece a efectos electroquímicos. como los producidos por las corrientes vagabundas procedentes de conducciones eléctricas mal aisladas (105).

\section{PARTE EXPERIMENTAL}

En el presente trabajo se ha tratado de estudiar, por vía experimental, la acción aceleradora ejercida por el cloruro cálcico sobre el 
fraguado $y$ endurecimiento de los morteros de cemento portland y arena, utilizados en la confección de piezas prefabricadas en taller.

El fin perseguido ha sido comprobar en qué medida y condiciones el empleo del cloruro cálcico como acelerador permite acortar los plazos de curado de los elementos prefabricados, aumentando el rendimiento de loș moldes, disminuyendo el número de los necesarios para una producción dada, anticipando la extracción de las piezas y su puesta en servicio, reduciendo el espacio necesario para su almacenamiento $y$, en suma, mejorando la productividad de las industrias de prefabricación de elementos de hormigón, al reducirse considerablemente la mano de obra necesaria en ellas, en virtud de lo expuesto.

Con tal objeto, el plan de trabajo experimental ha constado de dos partes: una primera, consistente en una serie de estudios previos de laboratorio, encaminados a encontrar por tanteo las condiciones óptimas de empleo del cloruro cálcico para el fin propuesto. La segunda tuvo por objeto comprobar en escala de taller los resultados hallados en la primera, para juzgar, desde un punto de vista práctico y real, la viabilidad de aplicatión de los mismos.

\subsection{Ensayos de laboratorio}

Se estudiaron y prepararon previamente los materiales, y se eligieron los métodos para la confección, curado y conservación de las probetas de mortero y pasta pura. Se determinaron las cargas de rotura de las mismas a compresión y tracción a diversas edades, tanto tempranas como más dilatadas, y se hicieron medidas de retracción.

\section{I.I. Los materiales}

En to que sigue, se exponen los detalles relativos a los materiales empleados en la confección del mortero utilizado para los ensayos.

\section{1.l.l. Mortero}

Se trabajó con mortero normal español, según las especificaciones del Pliego General de Con- diciones para la Recepción de Aglomerantes Hidráulicos en Obras de Carácter Oficial (8). La dosificación de este mortero es la siguiente:

Cemento: 600 gramos.

Arena: 1 litro (asentamiento normal).

Agua: la deducida de la fórmula: $Q=2 / 5 \mathrm{~N}+$ 93. en la que:

$Q=$ cantidad de agua para el mortero de 600 gramos de cemento y I litro de arena.

$\mathrm{N}=$ cantidad de agua para convertir $1 \mathrm{ki}-$ logramo de cemento en pasta pura de consistencia normal, según el correspondiente ensayo del mencionado Pliego.

Esta dosificación fué aceptada por dar los morteros que la poseen resistencias análogas a los de relación cemento/arena I:3, confeccionados con arena normal de Leucate, empleada en otro tiempo.

\subsubsection{Cemento}

Se utilizó un cemento español de altas resistencias iniciales (supercemento), con las siguientes caracteristicas:

Peso específico: 3,14

Residuos \% sobre tamices de:

900 mallas $/ \mathrm{cm}^{2}, 0,10 ; 4.900$ mallas $/ \mathrm{cm}^{2}, 1,90$; 10.000 mallas $/ \mathrm{cm}^{2}, 25,30$; polvo, 73,70 .

$\%$ de agua para obtener la pasta de consistencia normal: 29,6

Consistencia A. S. T. M.: $24 \%$

Tiempo de fraguado al aire:

$\begin{array}{ccc}\text { Principio } & \text { Fin } & \text { Duración } \\ 3 \mathrm{~h} 25 \mathrm{~m} & 5 \mathrm{~h} 10 \mathrm{~m} & \text { Ih } 45 \mathrm{~m}\end{array}$

Tiempo de fraguado bajo agua:

$$
\begin{array}{ccc}
\text { Principio } & \text { Fin } & \text { Duración } \\
2 \mathrm{~h} 15 \mathrm{~m} & 5 \mathrm{~h} 00 \mathrm{~m} & 2 \mathrm{~h} 45 \mathrm{~m}
\end{array}
$$

Superficie especifica Blaine: $3.620 \mathrm{~cm}^{2} / \mathrm{g}$

Expansión en autoclave: 0,15\% 
La consistencia A. S. T. M., la superficle específica Blaine y la expansión en autoclave se determinaron de acuerdo con los correspondientes métodos standard A. S. T. M. (4). La cifra de expansión es la media de las correspondientes a cuatro probetas.

Los demás resultados, incluidos los de los ensayos mecánicos y los del análisis químico que se dan a continuación en los cuadros 1.2 y 3 , se obtuvieron aplicando los métodos del Pliego español (83).

\section{U A D R O I}

\begin{tabular}{ccc} 
Edad & \multicolumn{2}{c}{ RESISTENCIAS MECANICAS } \\
Dias & Tracción: $\mathrm{kg} / \mathrm{cm}^{2}$ & Compresión: $\mathrm{kg} / \mathrm{cm}^{2}$ \\
I & 25 & 356 \\
2 & 28,5 & 419 \\
3 & 30,8 & 442 \\
7 & 31,8 & 496 \\
28 & 32,5 & 558
\end{tabular}

Las cifras indicadas son la media de tres valores concordantes correspondientes a tres probetas.

\section{$C U A D R O 2$}

$\begin{array}{cc}\text { Composición } & \begin{array}{c}\text { Análisis Quimico } \\ \text { (sobre muestra } \\ \text { desecada } \\ \%\end{array} \\ 105-110^{\circ} \mathrm{C} \text { ) }\end{array}$

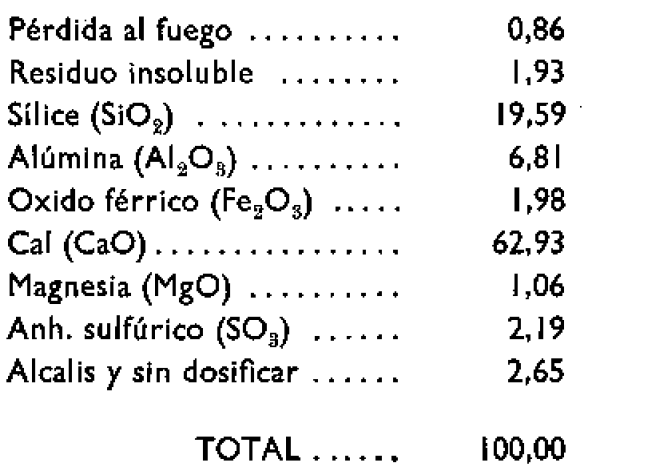

Humedad \% a $105-110^{\circ} \mathrm{C}: . . \quad 0,21$

Cal $(\mathrm{CaO})$ libre $\%: \ldots . . . \quad 0,00$

\section{U A D R O 3}

Composición potencial calculada $\quad \%$

Silicato tricálcico

$\mathrm{C}_{3} \mathrm{~S} \ldots \ldots \quad 52,4$

Silicato bicálciço $\quad C_{2} \$ \ldots .16,7$

Aluminato trícálcico $\quad \mathrm{C}_{9} \mathrm{~A} \ldots \quad . \quad 14,7$

Alumino-ferrito tetracálcico $\mathrm{C}_{4} \mathrm{AF} \ldots \quad 6,0$

La composición potencial se determinó aplicando a los datos del análisis químico los cálculos de Bogue (9).

\subsubsection{Arena}

Se empleó en la confección del mortero la arena seca normal del Manzanares que especifica el Pliego español. Es arena de río, silícea y monogranular, de tarnaño comprendido entre I y $1.5 \mathrm{~mm}$.

\subsubsection{Agua}

Se utilizó en los amasados agua potable de Madrid. Con ella se hicieron las disoluciones de cloruro cálcico empleadas en los correspondientes ensayos.

\section{I.I.5. Cloruro cálcico}

En la preparación de las disolucjones de cloruro cálcico se usó producto cristalizado, con 3,5-4 móleculas de agua de criștalización, en su calidad de quimicamente puro.

Una vez preparadas las disoluciones, se procedió en todo caso a su valoración, determinando su contenido de calcio para fijar exactamente su concentración de sal disuelta.

De las disoluciones, generalmente muy concentradas, se tomó en cada caso la cantidad necesaria para que en la totalidad del líquido de amasado el contenido de cloruro cálcico con relación al peso del cemento empleado fuese el preciso. El líquido de amasado fué siempre el mismo: 211,5 centímetros cúbicos por cada masa de 600 gramos de cemento y I hitro de 
arena, según se deduce de la cantidad de agua para lograr la consistencia normal de la pasta pura y de la fórmula anterior.

Si bien el cloruro cálcico contribuye a fluidificar la pasta haciendo precisa una menor cantidad de agua de amasado para conseguir una consistencia dada (23), no se tuvo en cuenta este hecho $y$, como se indica, se empleó en todos los casos el mismo volumen de líquido de amasado, aunque con distintas concentraciones de sal disuelta.

Para evitar posibles confusiones, dada la riqueza variable de cloruro cálcico $-\mathrm{CaCl}_{2}-$ en los productos comerciales, o en los hidratos o mezclas de hidratos con mayor o menor contenido de agua de cristalización, el porcentaje de cloruro cálcico con relación al peso del cemento se expresó siempre referido a sal anhidra. El cloruro ćlcico comercial, presentado en forma de escamas, suele tener una riqueza en sal anhidrà del 77 al $80 \%{ }^{(15)}$. Aparte de éste, tamblén se utiliza con análogos resultados el cloruro cálcico granulado (64).

Con arreglo a esto, en el cuadro 4 puede apreciarse la equivalencia entre porcentajes de sal anhidra y porcentajes del producto comercial con una riqueza del $80 \%$ en sal anhidra, así como la diferencia existente entre referir la adición \% a una $y$ otra forma de producto.

\section{U A D R O 4}

$\begin{array}{lll}\% \mathrm{CaCl}_{8} 100 \% & \begin{array}{c}\mathrm{CaCl}_{2} 100 \% \\ \left.\mathrm{CaCl}_{2} 80 \%\right)\end{array} & \% \mathrm{CaCl}_{2} 80 \% \\ 0 & 0 & 0 \\ 0,400 & 0,5 & 0,625 \\ 0,800 & 1 & 1,250 \\ 1,200 & 1,5 & 1,875 \\ 1,600 & 2 & 2,500 \\ 2,000 & 2,5 & 3,125 \\ 2,400 & 3 & 3,750 \\ 2,800 & 3,5 & 4,375 \\ 3,200 & 4 & 5,000 \\ 3,600 & 4,5 & 5,625 \\ 4,000 & 5 & 6,250 \\ 4,400 & 5,5 & 6,875 \\ 4,800 & 6 & 7,500\end{array}$

\subsubsection{Los métodos}

En las determinaciones de los tiempos de fraguado y de las resistencias mecániças se emplearon los métodos especificados en el Pliego español (23), salvo en los casos y circunstancias que más adelante se señalan.

\section{I.2.1. Fraguado}

Se determinaron los comienzos y finales de fraguado mediante la aguja de Vicat, aplicada a la pasta de consistencia normal que, como queda indicado, fué de $29,6 \%$ de agua.para el cemento empleado. No sólo se estudió el fenómeno en las condiciones normales del ensayo, es decir, manteniendo la probeta sumergida en agua, sino también mantenténdola al aire, en las condiciones de temperatura y humedad del laboratorio $\left(18 \pm 2{ }^{\circ} \mathrm{C}\right.$ y $\left.\mathrm{HR}=60 \%\right)$, más parecidas a las que se dan realmente en la utilización práctica del aglomerante.

\subsubsection{Confección de las probetas}

Se utilizaron tres tipos de probetas para cada uno de los sigulentes ensayos: rotura a compresión, rotura a tracción y retracción.

Para la rotura a compresión se confeccionaron probetas cúbicas de aproximadamente $7 \mathrm{~cm}$ de arista $\left(50 \mathrm{~cm}^{2}\right.$ de secçión). Se empleó mortero español amasado y compactado con arreglo al Pliego.

Para la rotura a tracción se hicieron las clásicas probetas en forma de ocho que aquél prescribe.

Para las medidas de retracción se confeccionaron probetas de pasta pura empleando los moldes y artificios que prescriben las normas de la A. S. T. M. para el ensayo de expansión en autoclave ${ }^{(5)}$, haciendo las mediciones de longitud de las probetas mediante el correspondiente comparador, cada división del cual corresponde a $0,00254 \mathrm{~mm}$.

\section{2,1.2.3. Curado y conservación}

Dado que se determinaron las resistencias mecánicas a edades muy cortas de las probetas 
(horas), y también a los plazos normales señalados en las normas (días), se adoptaron para el segundo caso las condiciones usuales de curado y conservación.

Así pues, las probetas enmoldadas se mantuvieron en cámara húmeda, prácticamente saturada de humedad y a $18+2{ }^{\circ} \mathrm{C}$, durante las primeras 24 horas a partir de su confección, y después, fuera del molde; sumergidas en agua dulce hasta el momento de la rotura.

En el primer caso se hizo una conservación por duplicado: unas series de probetas se mantuvieron enmoldadas $y$ dentro de la cámara húmeda, y otras enmoldadas y al aire, hasta el momento del ensayo. Tenía interés esto último por comprobar el posible efecto de la desecación en las primeras horas.

Las probetas para los ensayos de retracción se mantuvieron durante 24 horas enmoldadas y en cámara húmeda, $y$ el resto del tiempo fuera del molde $y$ en dicha cámara, salvo el instante de proceder a la medición de su longitud.

\subsubsection{Los resultados}

En lo que sigue se exponen, mediante cuadros y gráficos, los resultados obtenidos en cada uno de los diferentes tipos de ensayo llevados a cabo.

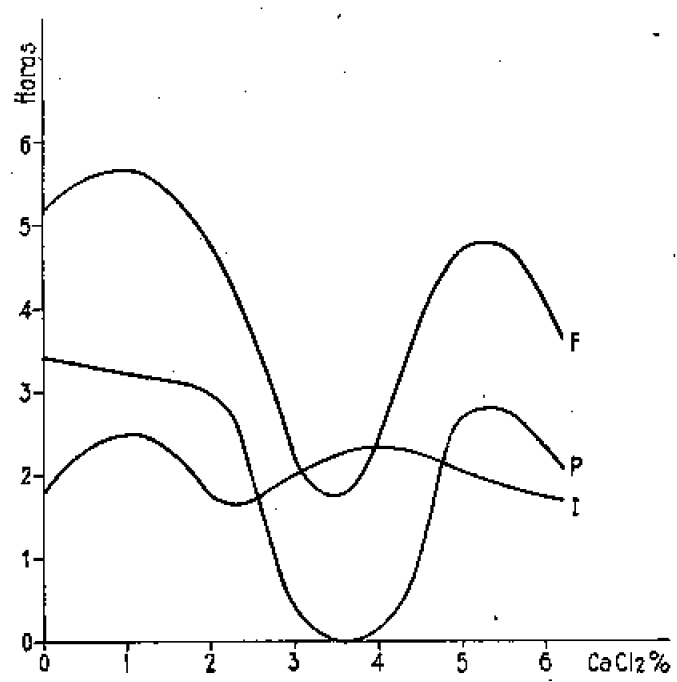

Fig. 1,-Principio (P), final (F) a intervalo (I) de fraguado, en función del contenido de $\mathrm{CaCl}_{\mathrm{g}}$ en el líquido de amasado de la pasta $(2||, 5$ c.c.)

\section{I.3.I. Fraguado}

En el cuadro 5 y figura I se dan y representan, respectivamente, los valores hallados para el principio, final e intervalo de fraguado de pastas puras de cemento, confeccionadas todas ellas con unà cantidad de líquido correspondiente a la pasta de consistencia normal con $0 \%$ de $\mathrm{CaCl}_{2}-2 \mathrm{Il}, 5$ c.c.-Dichos valores corresponden a contenidos de cloruro cálcico del porcentaje indicado, expresados en sal anhidra, en relación con el peso del cemento.

\section{U A D R O 5}

Fraguado al aire, a $18^{\circ} \mathrm{C}$

\begin{tabular}{ccccccc}
$\mathrm{CaCl}_{2}$ & \multicolumn{2}{c}{ Principio } & \multicolumn{2}{c}{ Final } & \multicolumn{2}{c}{ Intervalo } \\
$\%$ & horas & $\mathrm{mn}$ & horas & $\mathrm{mn}$ & horas & $\mathrm{mn}$ \\
0 & 3 & 25 & 5 & 10 & 1 & 45 \\
1 & 3 & 10 & 5 & 40 & 2 & 30 \\
2 & 3 & 05 & 4 & 50 & 1 & 45 \\
3 & 0 & 15 & 2 & 15 & 2 & 00 \\
4 & 0 & 00 & 2 & 20 & 2 & 20 \\
5 & 2 & 40 & 4 & 40 & 2 & 00 \\
6 & 2 & 20 & 4 & 05 & 1 & 45
\end{tabular}

Es de advertir que, tanto en estos ensayos de fraguado, como en los de resistencias mecánicas, la cantidad de líquido de amasado fué la misma en todos los casos, y no la correspondiente en cada uno a la consistencia normal. Ya se sabe que el cloruro cálcico modifica, según su concentración, la cantidad de líquido de amasado necesaria para conseguir, con una cantidad fija de cemento, una pasta de consistencia normal (TS). Por consiguiente, también modifica la cantidad de llquido de amasado necesaria para obtener. con cantidades filas de cemento y arena, un mortero de una plasticidad dada.

La figura I pone de relieve la existencia de dos mínimos que se corresponden entre si, en las curvas de principio (P) y final (F) de fraguado. Estos minimos se dan, más o menos, para un porcentaje de $\mathrm{CaCl}_{2}$ de 3,5. El intervalo de fraguado correspondiente (ordenada te la curva l) no es precisamente un mínimo en dicha curva, circunstancia favorable para el fraguado anticipado en tales condiciones.

La curva $F$ comienza siendo ascendente, to que indica que el cloruro cálcico, en dosis 


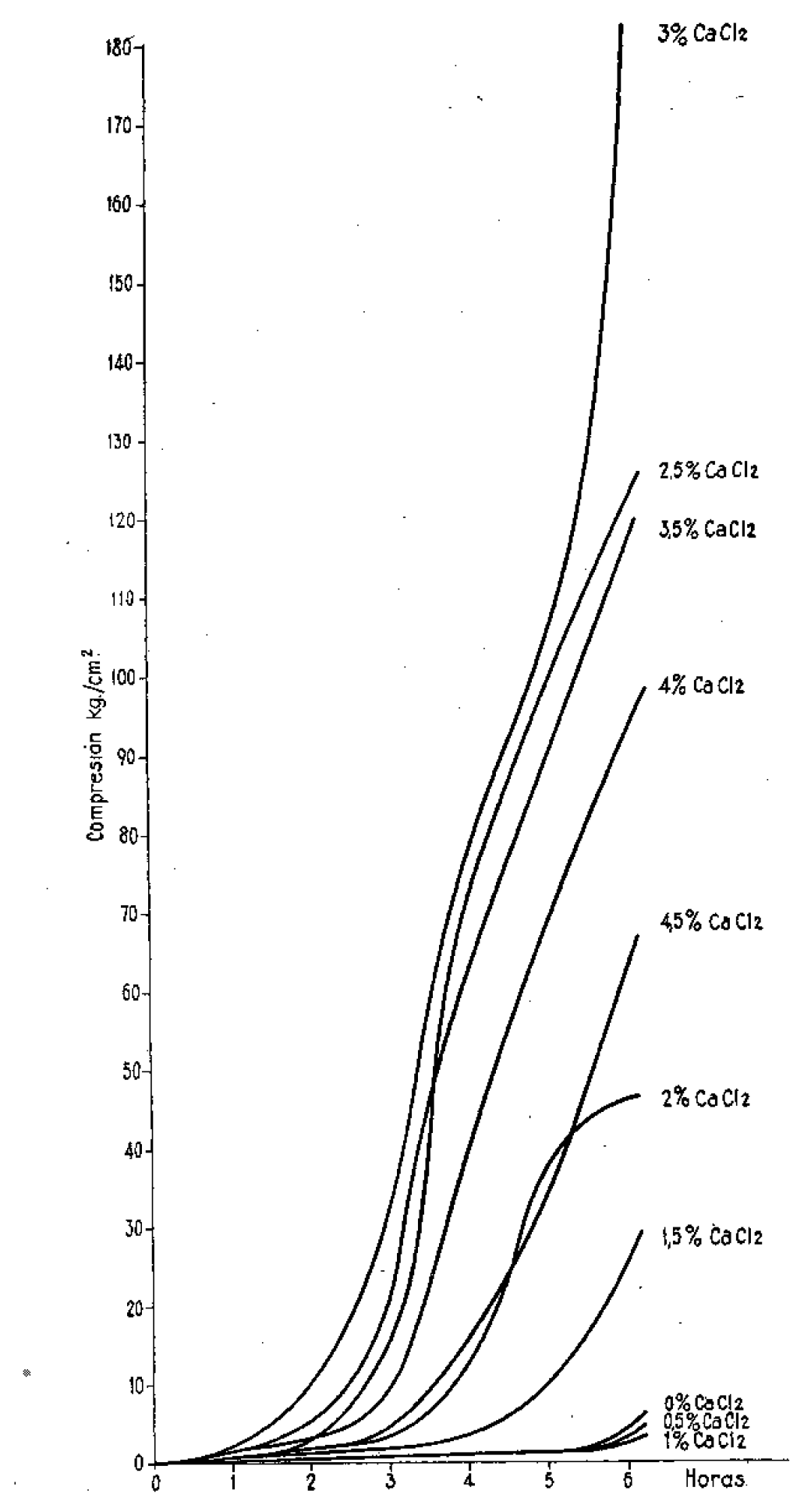

Fig. 2,-Resistencias a la compresión, a corto plazo, del mortero español, en función del porcentaje de $\mathrm{CaCl}_{2}$ con relaclón al peso de cemento. Curado al aire. 


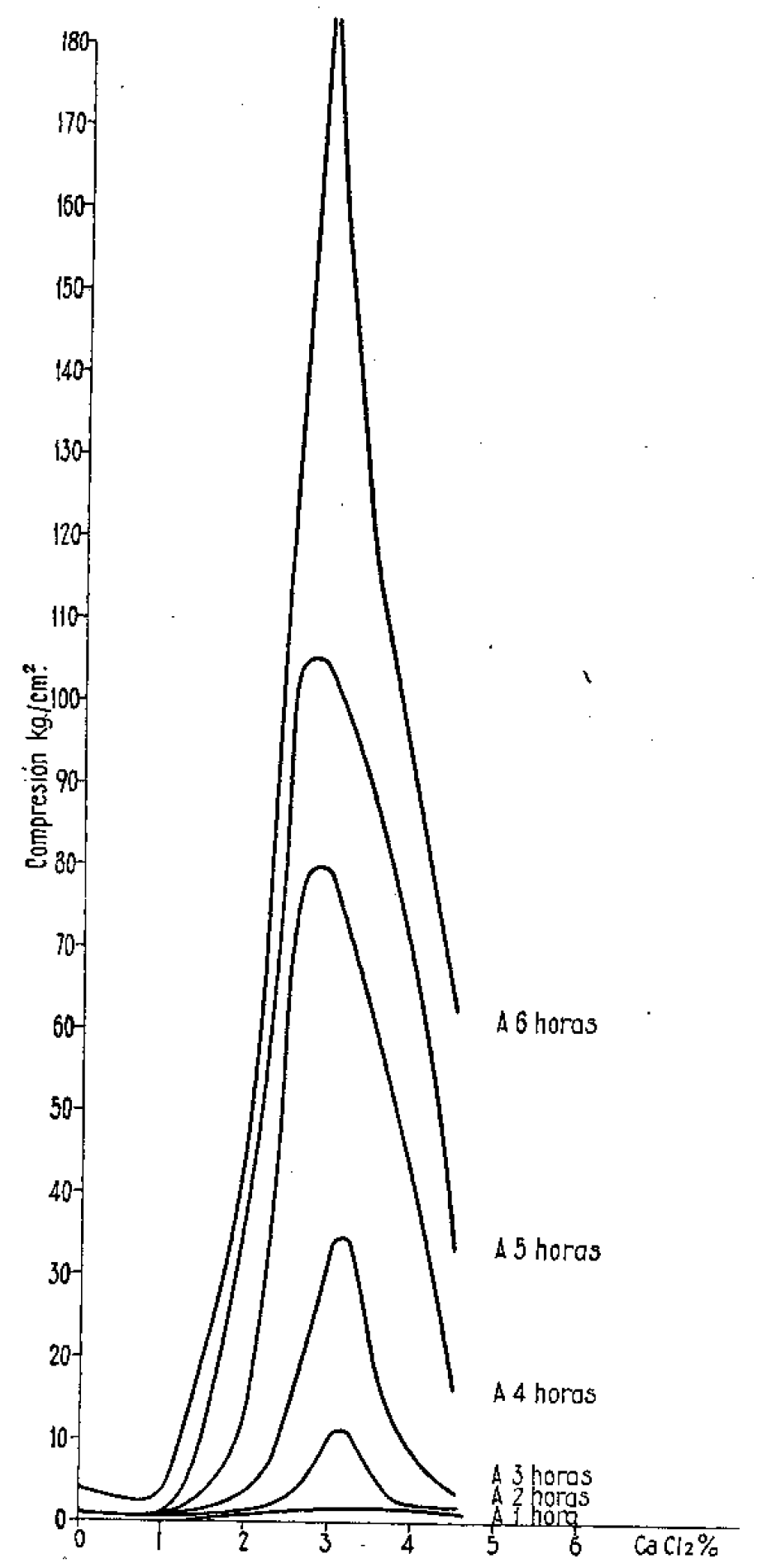

Fig. 3.-Resistencias a la compresión, a corto plazo, def mortero español, en función del porcentaje de $\mathrm{CaCl}_{2}$ con relación al peso de cemento. Curado al aire. 


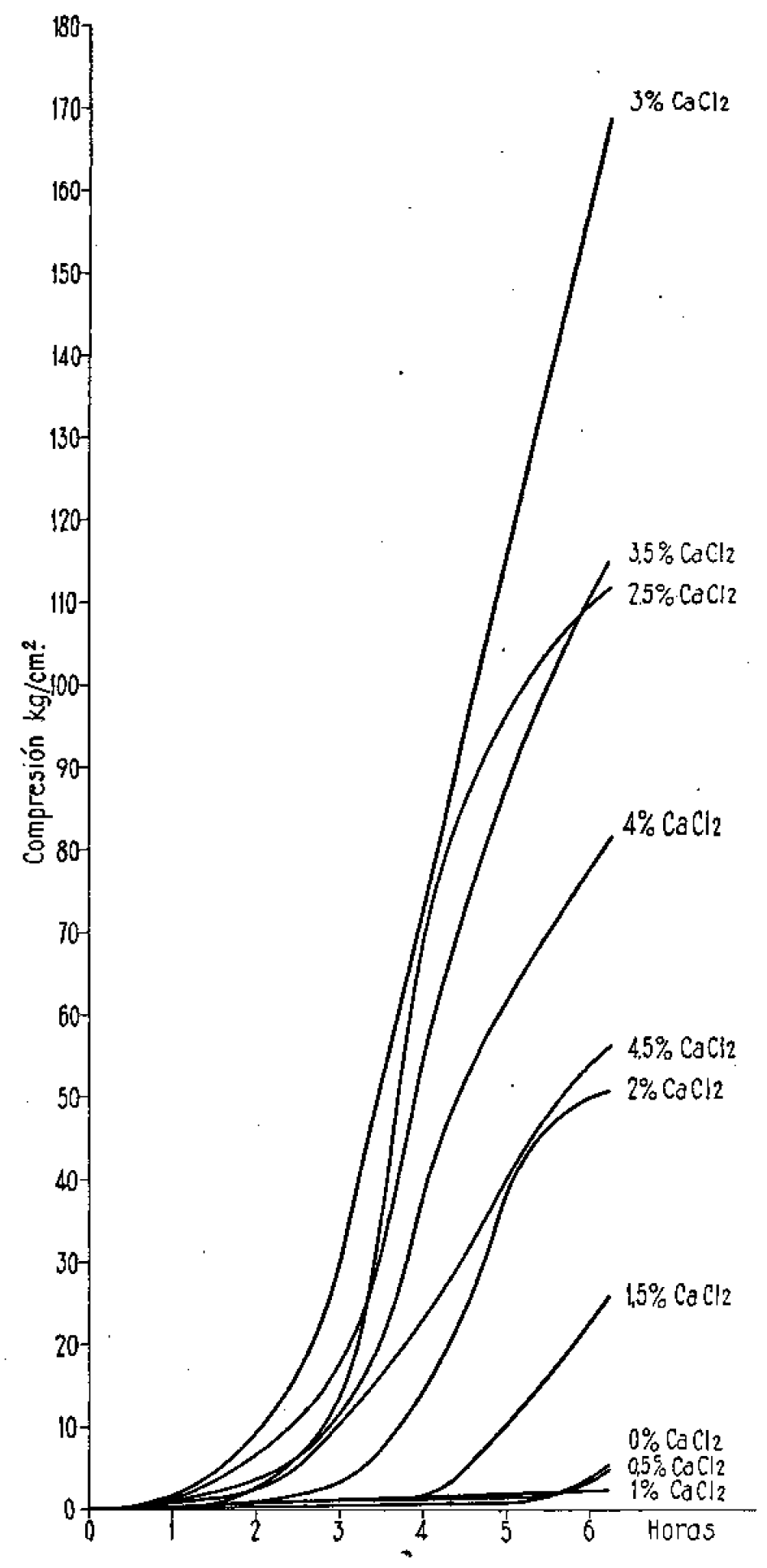

Fig. 4.-Resistencias a la compresión, a corţo plazo, del mortero español, en función del porcentaje de $\mathrm{CaCl}_{2}$ con relación al peso de cemento. Curado en cámara húmeda. 
hasta $1,5 \%$, actúa como retardador de fraguado. Tanto esto como lo anterior confirma los datos hallados por otros investigadores (véase 1.3).

\subsubsection{Resistencias mecánicas a corto plazo}

El objeto principal del trabajo, como ya se indicó, fué el de estudiar la acción de las adiciones de cloruro cálcico sobre las resistencias del mortero. con vistas a su empleo en prefabricación, a fin de acortar los plazos de curado.

Por ello, la determinación de las resistencias logradas mediante la adición del cloruro cálcleo. en las primeras horas de fraguado $y$ endurecimiento, constituyó la parte básica de la investigación.

Se determinaron las resistencias a la tracción y a la compresión, de hora en hora, entre una y seis horas, a partir de la operación de amasado, enmoldado y compactación del mortero.

Comoquiera que el factor que determina el que las piezas prefabricadas «tiernas» puedan ser manejadas sin peligro de fractura o fisuración en su resistencia a la tracción, se estudió ésta cuidadosamente, utilizando para la rotura de las probetas una balanza tipo Michaelis, especial, con dispositivo de velocidad de carga constante. Se trató de eliminar con ello una de las causas de dispersión en los resultados de roturas por tracción. Los resultados fueron, no obstante, dispersos, lo cual no es raro, dado el corto período de curado. Igual observación ha sido hecha con anterioridad, incluso para períodos de curado normales (10) (25),

A fin de tener junto a los datos que pudieran llamarse puramente «de laboratorio», otros más allegados a la realidad de la práctica de prefabrición en taljer, además del curado de estas probetas de corta edad en cámara húmeda se llevó a cabo el curado al atre de otra serie gemela de probetas.

Las figuras siguientes, particularmente las If y 13 , tienen más bien un valor esquemático, ya que los valores numéricos reales de las resistencias están señalados en los cuadros.

\subsection{A compresión}

Los resultados de los ensayos de rotura a compresión, a corto plazo, de probetas curadas al aire, se dan en el cuadro 6 y se representan gráficamente en las figuras 2 y 3.
La primera pone de relieve, en primer lugar, que la acción retardadora del fraguado ejercida por el cloruro cálcico en dosis de hasta $1 \%$. y puesta de manifiesto en la fig. l, se refleja también en las resistencias mecánicas a compresión durante las seis primeras horas de curado.

En segundo lugar demuestra la existencia de un valor óptimo en las dosificaciones de cloruro cálcico, desde el punto de vista del desarrollo de las resistencias a corto plazo. Dicho valor óptimo corresponde a una adición del $3 \%$ de $\mathrm{CaCl}_{2}$.

La figura 3 pone en evidencia los mismos hechos, si bien en ella la dosis óptima de $3 \%$ de $\mathrm{CaCl}_{2}$ se manifiesta en forma de máximo de las curvas.

Los resultados de los ensayos a compresión a corto plazo, de probetas curadas en cámara húmeda, se dan en el cuadro 7 y se representan gráficamente en las figuras 4 y 5 , análogas a las 2 y 3, respectivamente, $y$ en las que pueden observarse los mismos hechos que en aquéllas.

\subsection{A tracción}

Siguiendo análogo criterio, los resultados obtenidos se exponen en el cuadro 8 y figuras 6 y 7 , por lo que se refiere a las probetas conservadas al aire $y$ en el cuadro 9 y figuras 8 y 9 por lo que hace a las conservadas en cámara húmeda.

\section{$C \cup A D R O 6$}

\begin{tabular}{|c|c|c|c|c|c|c|}
\hline \multirow{2}{*}{$\begin{array}{c}\mathrm{CaCl}_{\mathrm{g}} \\
\%\end{array}$} & \multicolumn{6}{|c|}{$\begin{array}{l}\text { Curado al aire } \\
\text { Cargas de rotura a compresión: } \mathrm{kg} / \mathrm{cm}^{*}\end{array}$} \\
\hline & \multicolumn{6}{|c|}{ Horas } \\
\hline & 1 & 2 & 3 & 4 & .5 & 6 \\
\hline 0 & 0 & I & I & 1 & I & 4 \\
\hline 0,5 & 0 & 0,5 & 1 & 1 & 1 & 3 \\
\hline 1 & 0 & 0,75 & I & 1 & I & 2,5 \\
\hline 1,5 & 0,5 & 1 & 2 & 3 & 11 & 24,5 \\
\hline 2 & 1 & 1 & 3 & 13 & 38,5 & 46 \\
\hline 2,5 & i & 2,5 & 15 & 71,5 & 98 & 122,5 \\
\hline 3 & 1,5 & 10,5 & 33 & 78 & 102,5 & 187 \\
\hline 3,5 & 2 & 5,5 & 20 & 62,5 & 89,5 & 116,5 \\
\hline 4 & 2 & 2,5 & 8,5 & 40 & 67,5 & 92,5 \\
\hline 4,5 & 1,5 & 2 & 4 & 16 & 33 & 62,5 \\
\hline 5 & - & - & - & - & - & 一 \\
\hline 5,5 & - & - & - & - & - & - \\
\hline 6 & 一 & - & - & - & - & - \\
\hline
\end{tabular}




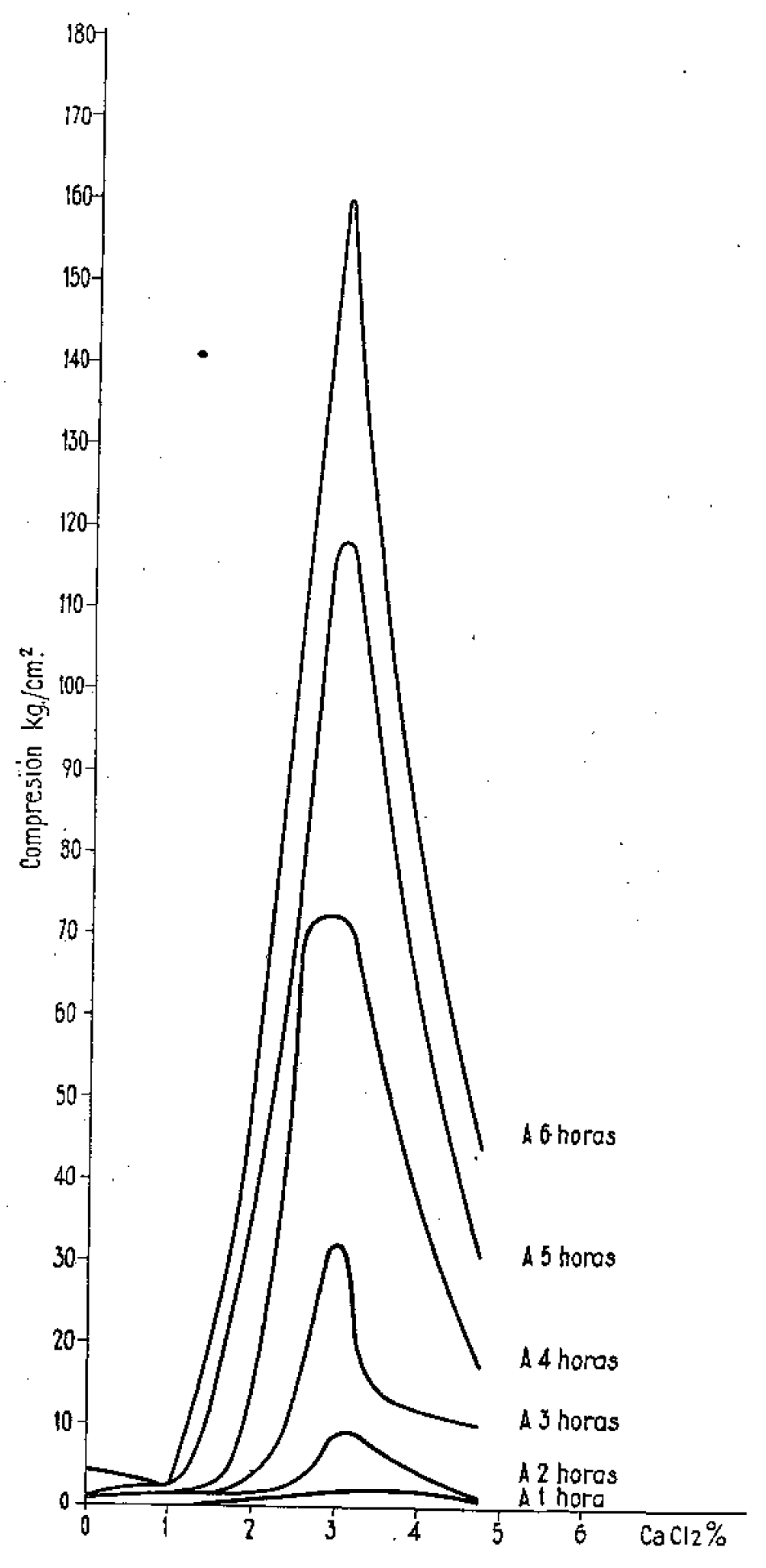

Fig, 5,-- Resistencias a la compresión, a corto plazo, del mortero español, en función dei porcentaje de $\mathrm{CaCl}_{y}$ con relación al peso de cemento. Curado en cámara húmeda. 


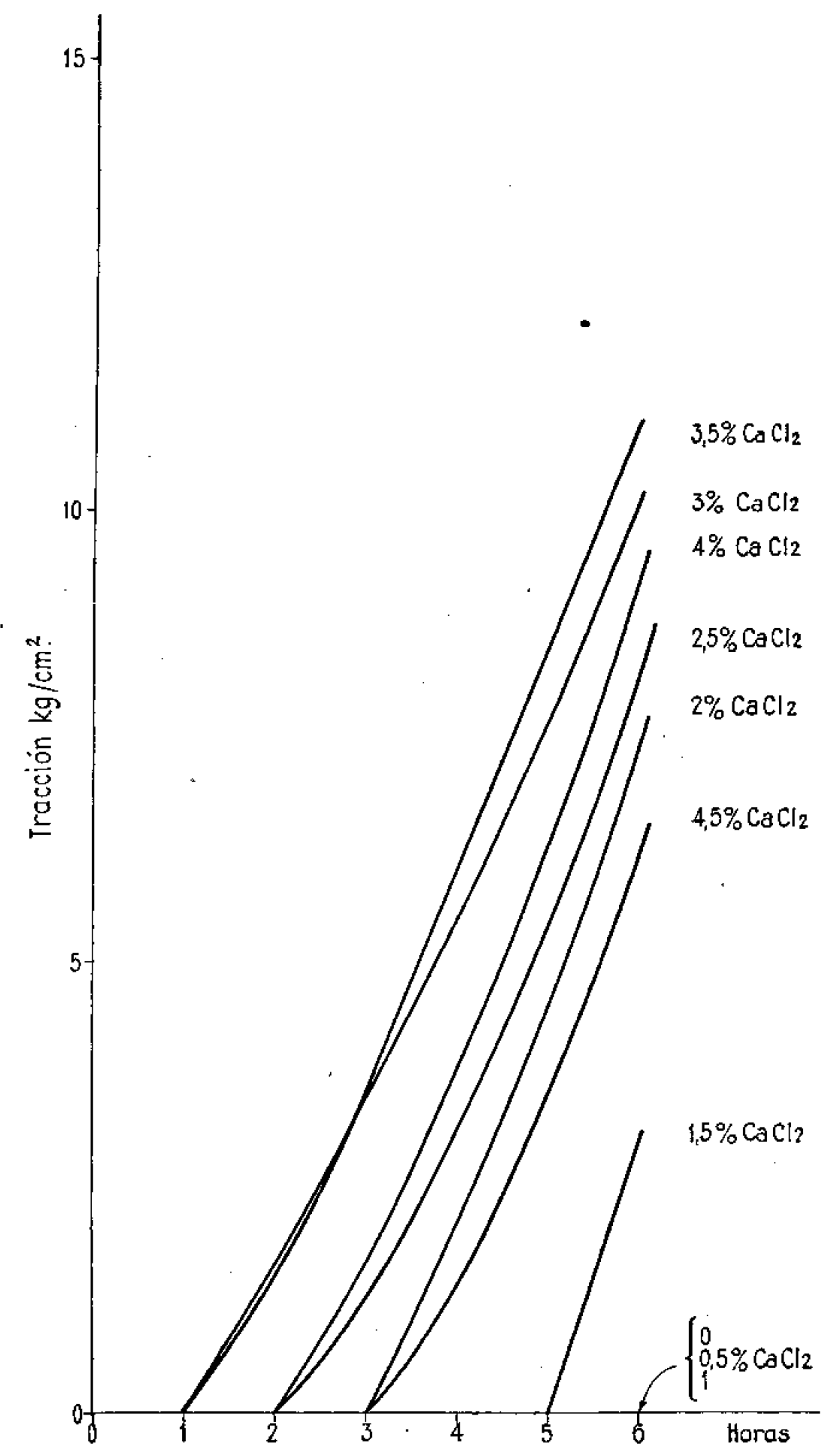

Fig. 6.-Resistencias a la tracción, a corto plazo, del mortero español, en función del porcentaje de $\mathrm{CaCl}_{2}$ con relación al peso de cemento. Curado al aire. 


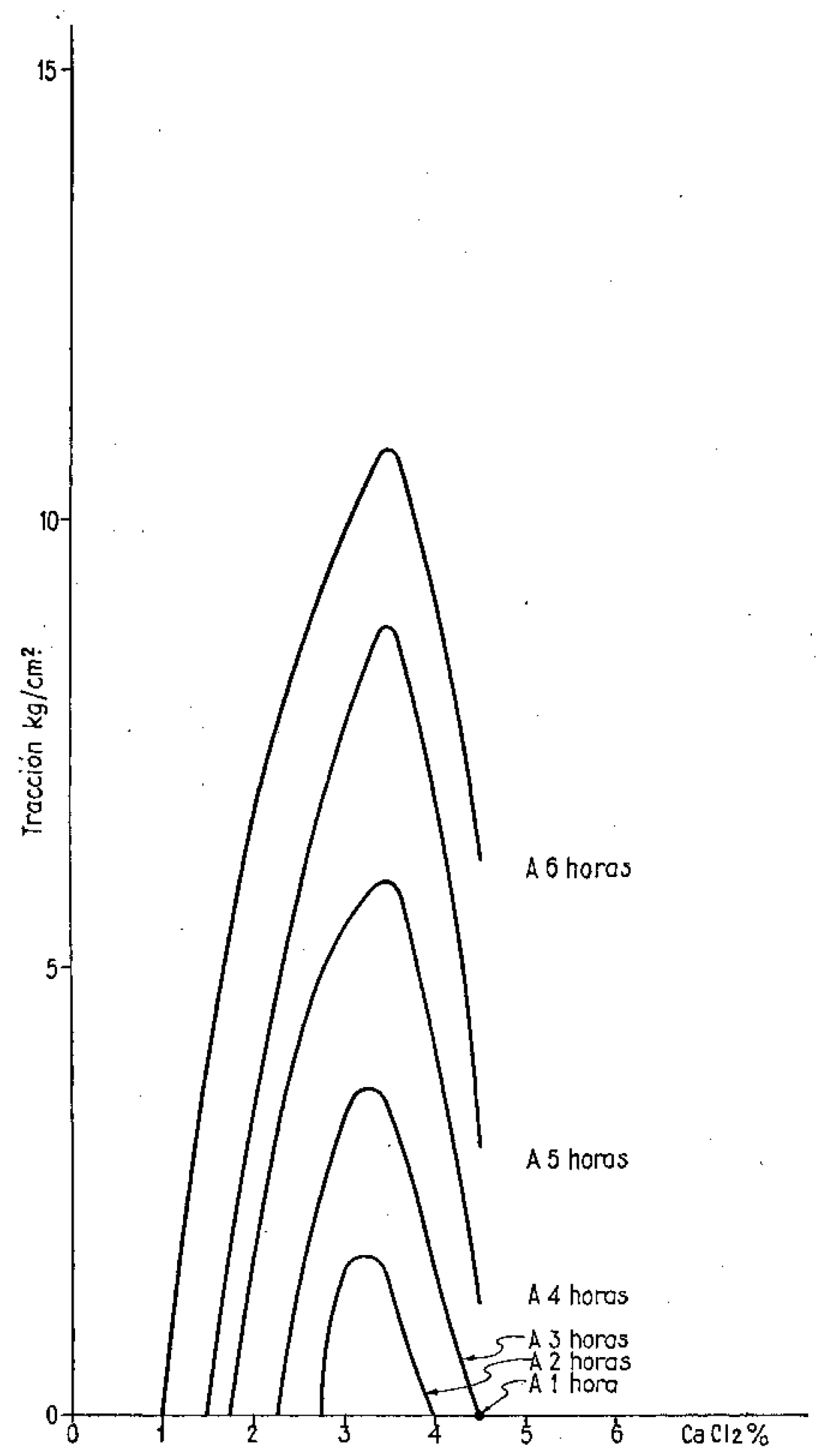

Fig. 7.-Resistenciass a la tracción, a corto plazo, del mortero español, en función del porcentaje de $\mathrm{CaCl}_{2}$ con relación al peso de cemento. Curado al aire.

37

(C) Consejo Superior de Investigaciones Científicas

Licencia Creative Commons 3.0 España (by-nc)

http://materconstrucc.revistas.csic.es 


\section{U A D R O 7}

Curado en cámara húmeda

\begin{tabular}{ccccccc}
$\mathrm{CaCl}$, & \multicolumn{6}{c}{ Cargas de rotura a comprestín $\mathrm{kg} / \mathrm{cm}^{2}$} \\
$\%$ & \multicolumn{7}{c}{ H o r a s } \\
& 1 & 2 & 3 & 4 & 5 & 6 \\
0 & 0 & 1 & 1 & 1 & 1 & 4 \\
0,5 & 0 & 0 & 1 & 1 & 2 & 3,5 \\
1 & 0 & 0 & 1,5 & 1,5 & 2 & 2 \\
1,5 & 0 & 1 & 1,5 & 2 & 11 & 22,5 \\
2 & 0,75 & 1,5 & 3 & 14 & 38,5 & 50,5 \\
2,5 & 1 & 2,5 & 13 & 69 & 96 & 110 \\
3 & 2 & 9 & 32 & 72,5 & 118 & 160,5 \\
3,5 & 1,5 & 7 & 14 & 69 & 87,5 & 111,5 \\
4 & 2 & 4 & 11 & 40 & 60 & 78,5 \\
4,5 & 2 & 4 & 11 & 23 & 40 & 53,5 \\
5 & - & - & - & - & - & - \\
5,5 & - & - & - & - & - & - \\
6 & - & - & - & - & - & -
\end{tabular}

\section{U A D R O 8}

Curado al aire

\begin{tabular}{lllllll}
$\begin{array}{c}\mathrm{CaCl}_{2} \\
\%\end{array}$ & \multicolumn{6}{c}{ Cargas de rotura a tracción $\mathrm{kg} / \mathrm{cm}^{2}$} \\
& 1 & 2 & 3 & 4 & 5 & 6 \\
0 & 0 & 0 & 0 & 0 & 0 & 0 \\
0,5 & 0 & 0 & 0 & 0 & 0 & 0 \\
1 & 0 & 0 & 0 & 0 & 0 & 0 \\
1,5 & 0 & 0 & 0 & 0 & 0 & 3 \\
2 & 0 & 0 & 0 & 2 & 4,6 & 7,4 \\
2,5 & 0 & 0 & 1,3 & 3,2 & 5,4 & 8,1 \\
3 & 0 & 1,6 & 3,4 & 5,6 & 7,6 & 10 \\
3,5 & 0 & 1,5 & 3,5 & 6 & 8,4 & 10,8 \\
4 & 0 & 0 & 1,7 & 3,8 & 6,3 & 9,2 \\
4,5 & 0 & 0 & 0 & 1,5 & 3,5 & 6,2 \\
5 & - & - & - & - & - & - \\
5,5 & - & - & - & - & - & - \\
6 & - & - & - & - & - & -
\end{tabular}

\section{U A D R O}

Curado en cámara húrneda

\begin{tabular}{ccccccc}
$\mathrm{CaCl}_{2}$ & \multicolumn{6}{c}{ Cargas de rotura a tracción $\mathrm{kg}^{\prime} \mathrm{cm}^{4}$} \\
& 1 & 2 & 3 & 4 & 5 & 6 \\
0 & 0 & 0 & 0 & 0 & 0 & 0 \\
0,5 & 0 & 0 & 0 & 0 & 0 & 0 \\
1 & 0 & 0 & 0 & 0 & 0 & 0 \\
1,5 & 0 & 0 & 0 & 0 & 0 & 2,6 \\
2 & 0 & 0 & 0 & 2,2 & 4 & 5,6 \\
2,5 & 0 & 0 & 1,3 & 3,2 & 5,6 & 8,6 \\
3 & 0 & 1 & 2,4 & 4,4 & 7 & 10,4 \\
3,5 & 0 & 1 & 2,8 & 5,8 & 8,5 & 10,6 \\
4 & 0 & 0 & 1,8 & 4 & 6,5 & 9,5 \\
4,5 & 0 & 0 & 0 & 1,9 & 3,1 & 4,2 \\
5 & - & - & - & - & - & - \\
5,5 & - & - & - & - & - & - \\
6 & - & - & - & - & - & -
\end{tabular}

Son de observar los mismos hechos apreciados en los resultados de rotura a compresión, sl bien en este caso la dosis óptima de $\mathrm{CaCl}_{2}$ se desplaza hacia el valor de 3,5\%.

\section{I.3.3. Resistencias mecánicas a largo plazo}

Como complemento de los ensayos a corto plazo, se determinaron también las resistencias a compresión y tracción a $1,2,3,7$ y 28 dias. con objeto de ver si las distintas dosis de cloruro cálcico ensayadas a corto plazo podían ser nocivas para las resistencias a los plazos normales de curado. En estos ensayos sólo se utilizaron probetas conservadas en cámara húmeda.

\subsubsection{I. A compresión}

Los resultados de los correspondientes ensayos se exponen en el cuadro $10 \mathrm{y}$ figuras 10 y 11. Las curvas de la primera no presentan la marcha de las de la figura 2, sino que se cruzan entre sí. A 28 dias las probetas con porcentajes de $\mathrm{CaCl}_{z}$ hasta $4 \%$ dan igual o mayor resisten- 


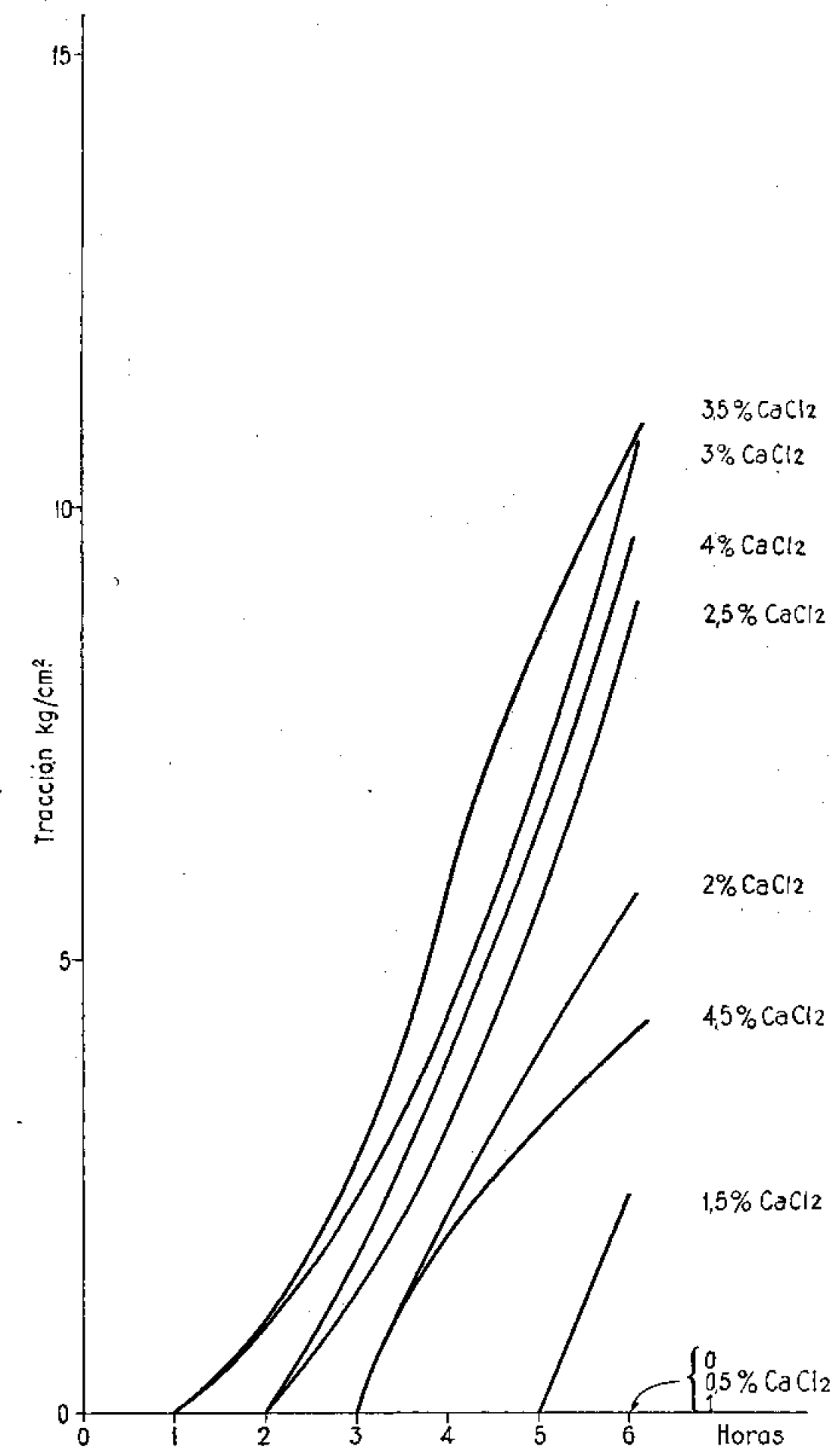

Fig. 8.-Resistencias a la traceión, a corto plazo, del mortero español, en función del porcentaje de $\mathrm{CaCl}_{\mathbf{1}}$ con relación al peso de cemento. Curado en cámara húmeda. 


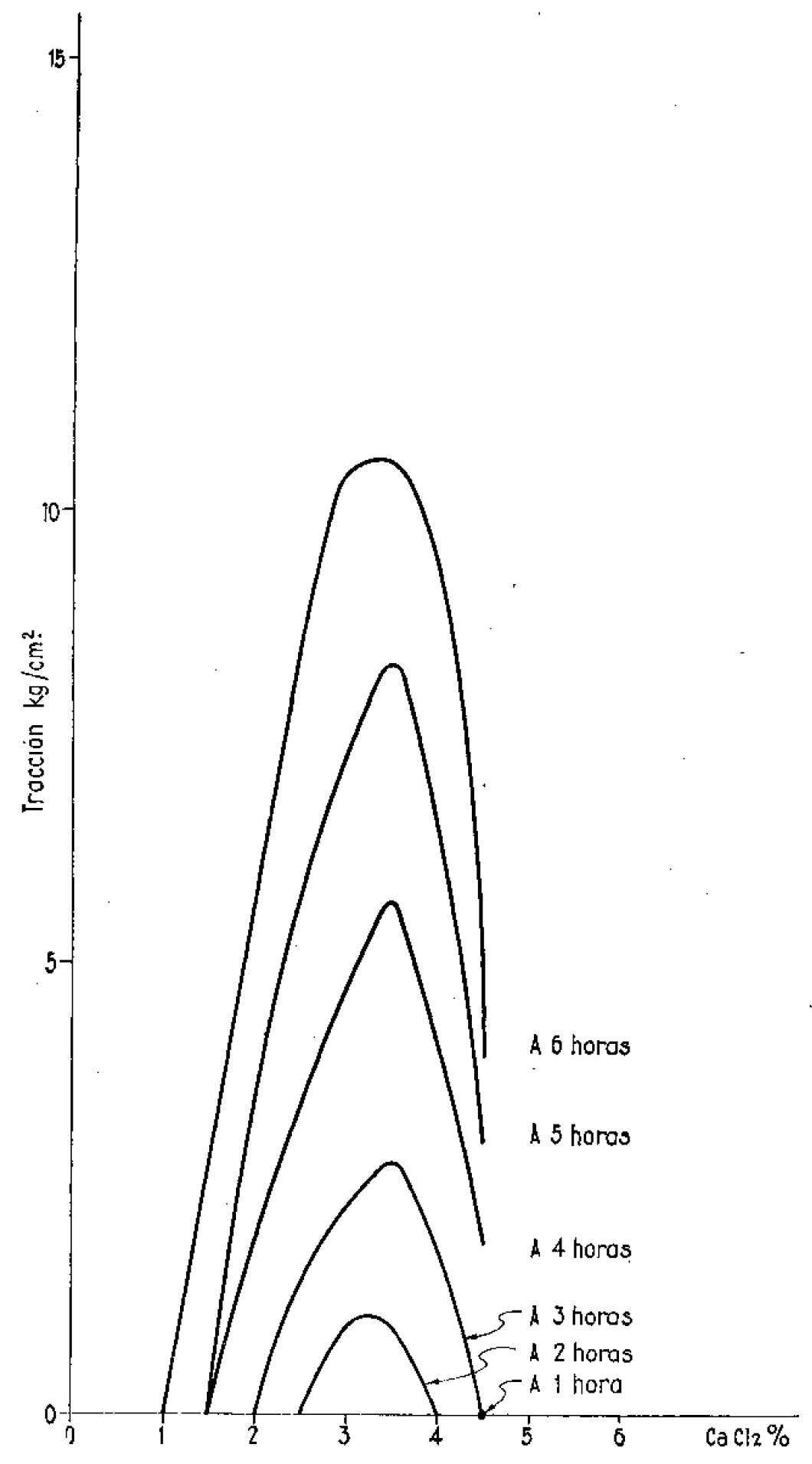

Fig. 9.-Resistenclas a la tracción, a corto plazo, del mortero español, en función del porcentaje de $\mathrm{CaCl}_{2}$ con relactón al peso de cemento, Curado en cámara húmeda. 
cia que las que no contieneh ninguna adición del producto, $y$ menor las de porcentajes superiores a dicho valor.

A edades más cortas los hechos se aprecian mejor en la figura II que pone de relieve una caída de resistencia a 1,2 y 3 dias, para una adición de $1 \%$ de $\mathrm{CaCl}_{2}$. Esto concuerda con el efecto retardador de dicha dosis, antes se- ñalado. A 7 y 28 días no sucede así. Por otra parte, los máximos de estas curvas indican que la dosis óptima de $\mathrm{CaCl}_{2}$ se desplaza hacia el valor de $2 \%$ a edades normales, apreciándose, no obstante, que la de $3 \%$ sigue proporcionando resistencias mayores que la dosis nula, en general a cualquier edad de las estudiadas, como se aprecia también en la figura 10 .

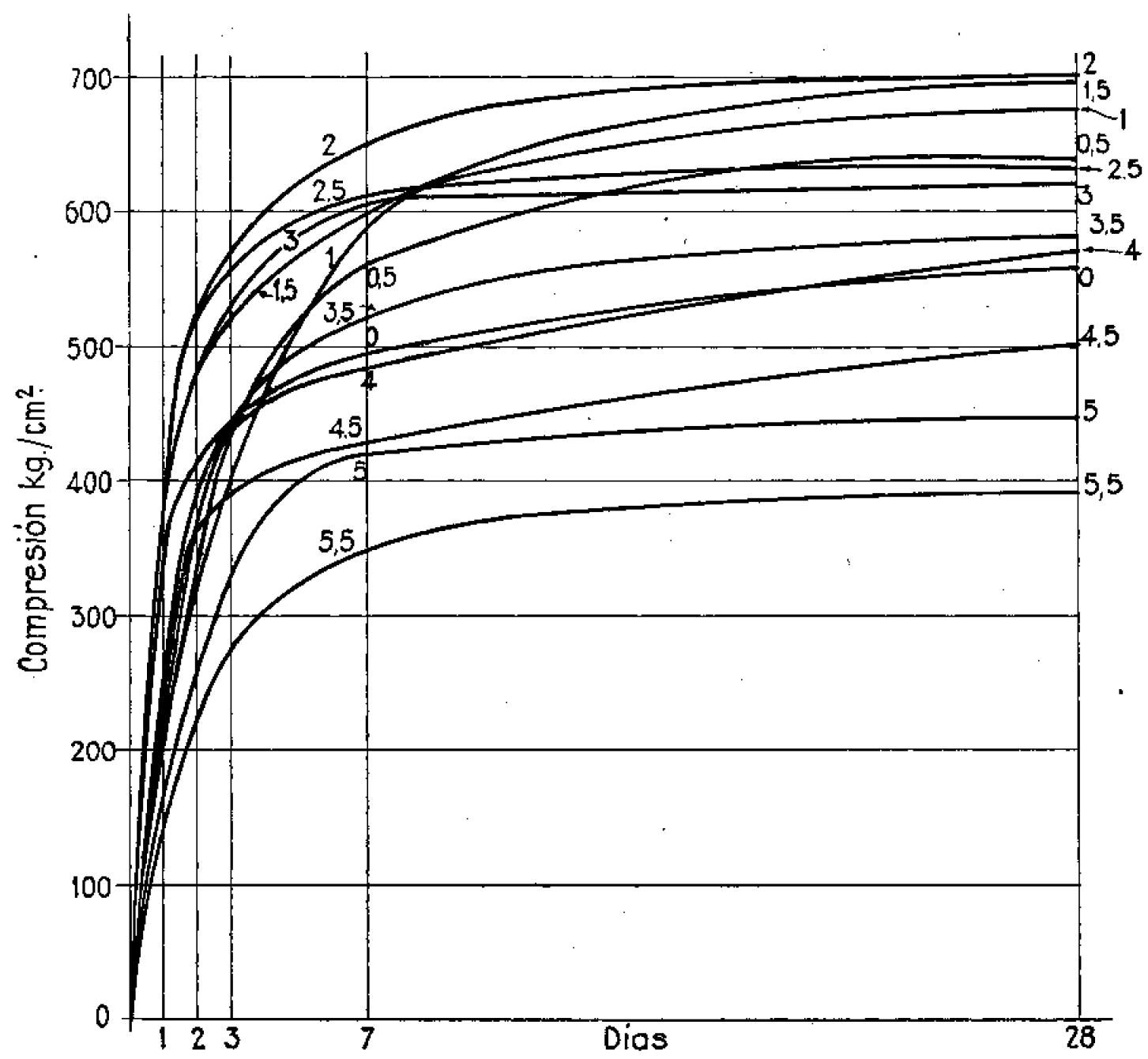

Fig. 10.-Resistencias a la compresión, a plazos normales, del mortero español, en función del porcentaje de $\mathrm{CaCl}_{3}$ con relación al peso de cemento. Curado en cámara húmeda. 


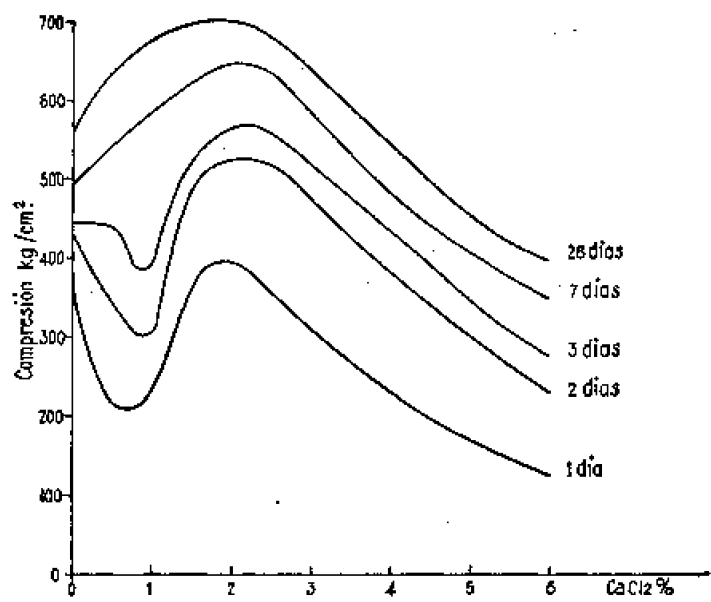

Fig. II.-Resistencias a la comprestón, a plazos normales, del mortero español, en función del porcentaje de $\mathrm{CaCl}_{2}$ con relación al peso de cemento. Curado en cámara húmeda.

\section{U.A D R O IO}

\begin{tabular}{lccccc}
$\mathrm{CaCl}$ & \multicolumn{5}{c}{ Cargas de rotura a compresión $\mathrm{kg} / \mathrm{cm}^{7}$} \\
$\%$ & \multicolumn{5}{c}{$\mathrm{D} \mathrm{i} \mathrm{a} \mathrm{s}$} \\
& $\mathrm{I}$ & 2 & 3 & 7 & 28 \\
0 & 356 & 419 & 442 & 496 & 558 \\
0,5 & 218 & 357 & 445 & 562 & 640 \\
$\mathrm{I}$ & 233 & 312 & 400 & 595 & 675 \\
1,5 & 366 & 488 & 520 & 599 & 696 \\
2 & 397 & 525 & 570 & 656 & 700 \\
2,5 & 352 & 520 & 560 & 615 & 630 \\
3 & 335 & 480 & 522 & 614 & 620 \\
3,5 & 255 & 400 & 450 & 520 & 580 \\
4 & 252 & 384 & 445 & 480 & 571 \\
4,5 & 196 & 366 & 397 & 430 & 500 \\
5 & 170 & 240 & 340 & 420 & 445 \\
5,5 & 145 & 265 & - & - & 459 \\
6 & - & - & - & - & -
\end{tabular}

\subsection{A tracción}

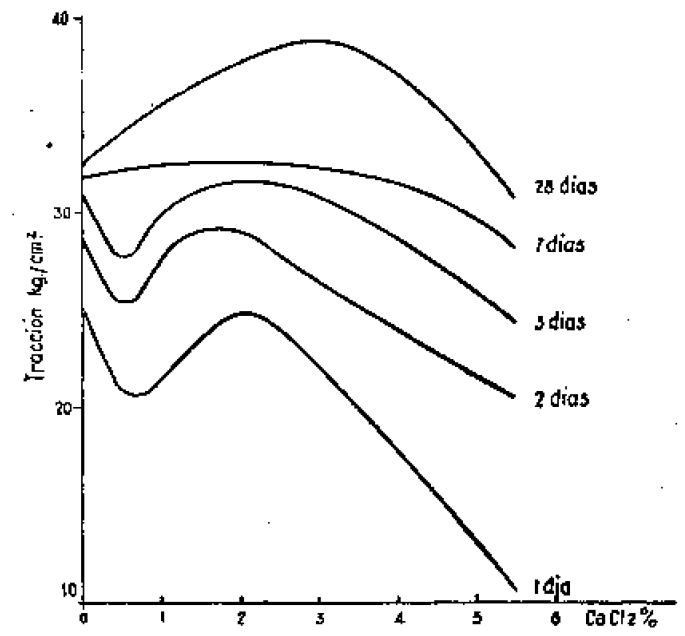

Fig. 13.-Resistencias a la tracción, a plazos normales, del mortero español, en función del porcentaje de $\mathrm{CaCl}_{2}$ con relación al peso de cemento. Curado en cámara húmeda.
Los ensayos a tracción dieron por resultado los valores del cuadro II y las figuras 12 y 13 .

En estas se aprecian los mismos hechos generales ya mencionados al tratar de los ensayos a compresión, saivo pequeñas diferencias de matiz cuantitativo. Sin embargo, es de destacar la circunstancia de que, a 28 días, con cualquiera de los porcentajes de $\mathrm{CaCl}_{2}$ estudiados, las resistenclas son mayores que las correspondientes a la adición de $0 \%$. No sucede otro tanto a edades más cortas, particularmente por lo que se refiere a las adiciones de $\mathrm{CaCl}_{2}$ más elevadas.

Todo cuanto queda expuesto respecto de los resultados encontrados al estudiar las resistencias mecánicas a corto y largo plazo, confirma, en general, lo hallado por otros autores. Tan sólo discrepa de los resultados de algunos, según los cuales las resistencias a la tracción apenas se mejoran con el empleo de cloruro cálcico (véase l.3). 


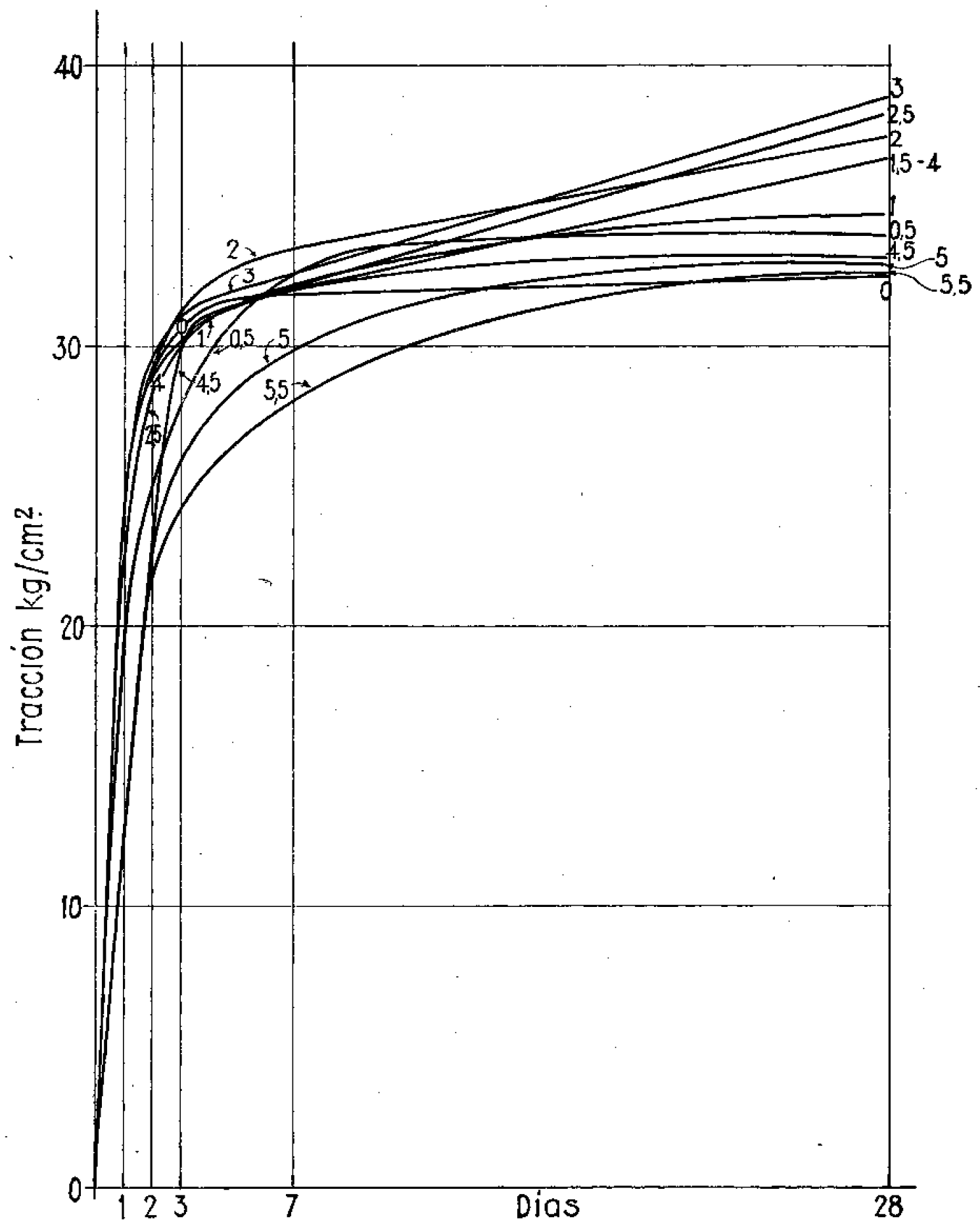

Fig. 12.-.-Resistencias a la tracción, a plazos normales, del mortero español, en funclón del porcentaje de $\mathrm{CaCl}_{2}$ con relación al peso de cemento. Curado en cámara húmeda. 


\section{CUADRO I I}

\begin{tabular}{lccccc}
$\mathrm{CaCl}_{2}$ & \multicolumn{5}{c}{ Cargas de rotura a tracción $\mathrm{kg} / \mathrm{cm}^{\mathrm{q}}$} \\
$\%$ & \multicolumn{5}{c}{$\mathrm{D} \mathrm{i} \mathrm{a} \mathrm{s}$} \\
& 1 & 2 & 3 & 7 & 28 \\
0 & 25 & 28,5 & 30,8 & 31,8 & 32,5 \\
0,5 & 20,8 & 25,4 & 27,7 & 32,7 & 34 \\
1 & 21,6 & 28,8 & 30 & 32,2 & 34,8 \\
1,5 & 23,4 & 29 & - & 32 & 36,8 \\
2 & 24,8 & 29,5 & 31,6 & 33,5 & 37,6 \\
2,5 & 19,8 & 27,7 & 30 & 32,1 & 38,4 \\
3 & 21,7 & 29 & 31,5 & 32,5 & 39 \\
3,5 & - & - & 25,9 & 31,4 & 32,2 \\
4 & 18 & 29 & - & 32,2 & 36,8 \\
4,5 & 13 & 22,8 & 30 & 32 & 33,2 \\
5 & 12,7 & - & 25,8 & 30 & 33 \\
5,5 & 10,5 & 21 & 24,3 & 28,1 & 32,7 \\
6 & - & - & - & - & -
\end{tabular}

\subsubsection{Medidas de retracción}

El problema de la retracción tiene gran importancia en los prefabricados de hormigón, particularmente en los elementos estructurales que cumplen a la vez una misión ornamental.

Es sabido que la retracción depende, aparte de otras circunstancias, de la dosis de cemento, siendo mayor en pastas puras que en morteros. $y$ en éstos que en hormigones.

Depende también de la naturaleza y dosis en que intervengan las adiciones utilizadas para conseguir determinados fines.

Por todo ello, se consideró interesante estudiar comparativamente la retracción de pastas puras con y sin adiclón de cloruro cálcico, en probetas de características que ya quedaron indicadas.

Se tuvo en cuenta la dosis de $3 \%$ de $\mathrm{CaCl}_{2}$, por ser ésta la que mejores resultados dió en los ensayos mećánicos a corto plazo, sin ser perjudi- cial para las resistencias a plazos normales, antes bien mejorándolas.

Se hicieron medidas de retracción cada 24 horas, por un espacio de 90 días, a partir del momento en que las correspondientes probetas fueron sacadas de los moldes (a las 24 horas de su confección).

Los resultados quedan de manifiesto en la figura 14 , en la que cada curva es la media de los resultados de seis probetas. Se señalan también los valores extremos presentados por cada haz de seis curvas.

Puede observarse que, en el caso de las probetas sin cloruro cálcico, la retracción aumenta durante los 9 primeros días, más rápidamente al principio, estabilizándose prácticamente después en un valor medio aproximado a $0,8 \%$ $(0,8 \mathrm{~mm}$ por $\mathrm{m})$.

En las probetas de $3 \%$ de $\mathrm{CaCl}_{9}$, que presentan una dispersión de valores algo mayor, tiene lugar una retracción pequeña al principio, durante los tres primeros días, que disminuye continuamente después y se hace nula al cabo de los 15 días. A partir de entonces, se presenta una expansión continuamente creciente, que se estabiliza al cabo de 65 días en un valor medio de $0,6 \%$ o $(0,6 \mathrm{~mm}$. por $\mathrm{m})$. La curva de puntos sería la de la expansión absoluta provocada por el cloruro cálcico, independiente de la retracción que se superpone.

La presencia de cloruro cálcico parece modificar, por tanto, el comportamiento de la pasta en el aspecto de la retracción.

\subsection{Experiencias de taller}

Una vez deducida de los ensayos de laboratorio la dosis óptima de cloruro cálcico a emplear, y que, como ya queda indicado, fué la de $3 \%$ referido a sal anhidra, se procedió a aplicarla a las piezas confeccionadas en taller, en la forma $y$ con los detalles que se especifican en lo que sigue.

\section{2,1. Las piezas prefabricadas}

Se confeccionaron marcos de ventana, de mortero armado y vibrado, con una luz de unos $120 \times 150 \mathrm{~cm}$ al exterior y $115 \times 105$ al inte- 


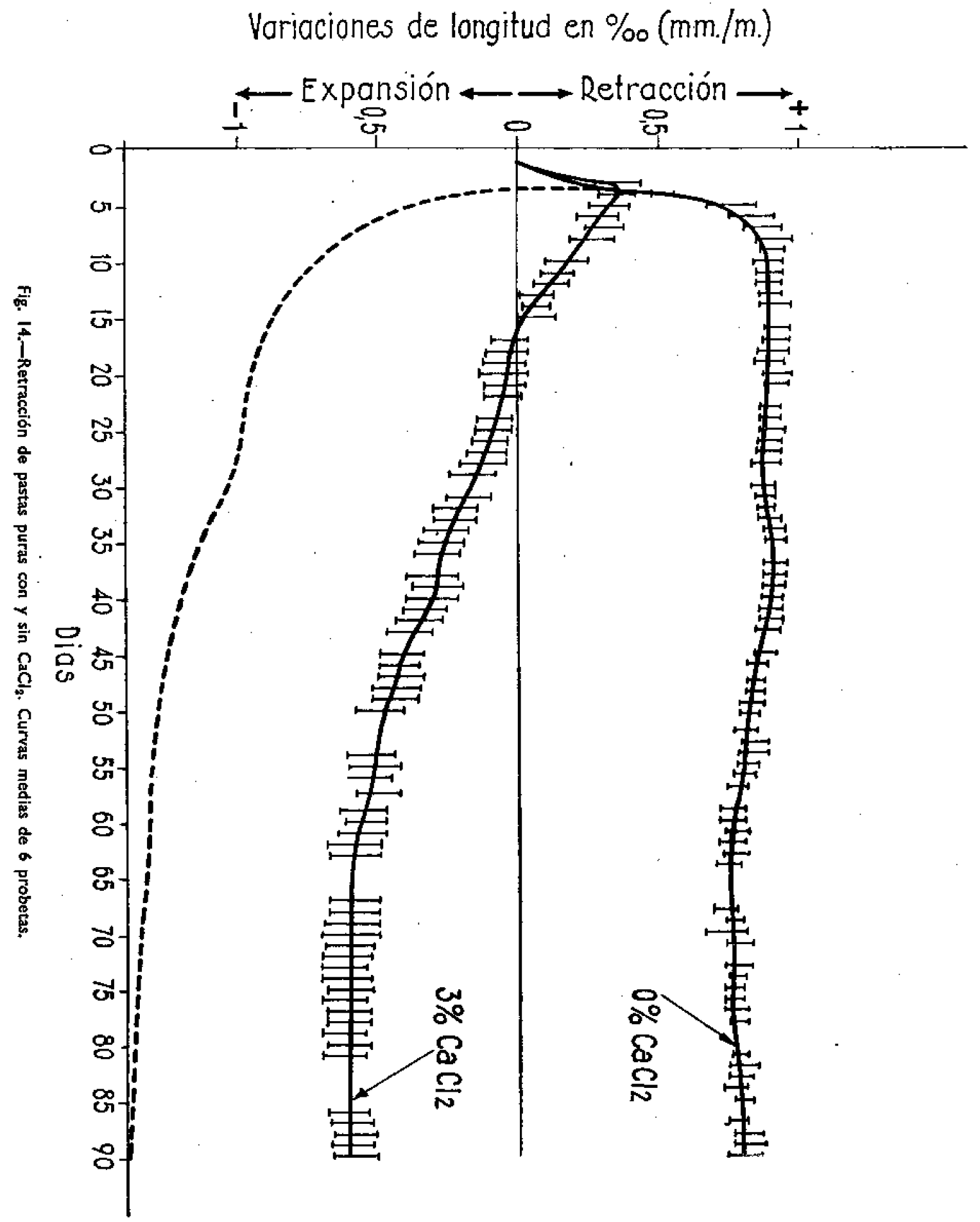


rior y el aspecto, una vez confeccionados, que puede apreciarse en la fig. 15.

Los marcos pesaban, aproximadamente, 210 kilogramos, e iban provistos de un cargadero de $9 \times 22 \times 155 \mathrm{~cm}$, fuertemente armado. Las secciones del alféizar, jambas $y$ marco interior oscilaban entre 3 y $4 \mathrm{~cm}$.

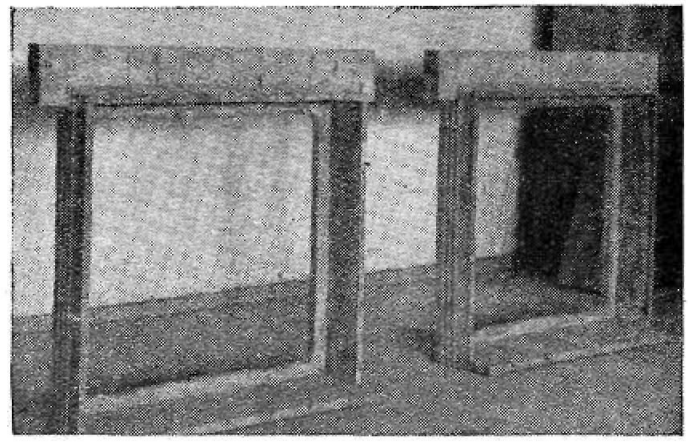

Fig. 15.-Marcos de ventana prefabricados. Hormigón armado y vibrado.

Se trata de piezas difíciles, tanto por su for$\mathrm{ma}$, dimensiones y peso, como por el desigual reparto de masas y sus relativamente delgadas secciones.

\subsubsection{Los materiales}

En algunos aspectos difieren, naturalmente, de los utilizados en los ensayos de laboratorio.

\subsubsection{Mortero}

No se empleó, como es lógico, el mortero normal español, sino uno constituido, aproximadamente, por 74 partes de cemento y 100 partes de arena, en peso, y 25 litros de agua*, por cada marco. De tal manera, que las relaciones de los distintos materiales vinieron a ser las siguientes:

$$
\begin{aligned}
& \text { cemento/arena }=0,75 \\
& \text { agua/cemento }=0,33^{*}
\end{aligned}
$$

- Al confeccionar los marcos sin adición de cloruro cálcico la cantidad de agua de amasado fué de 30 litros, por término medio, con lo que la relación aguajcemento llegó a 0,40 .

\subsubsection{Cemento}

En general se utilizó el mismo supercemento que para los ensayos de laboratorio, es decir, con las características señaladas en 2.I.1.2.

Con motivo de haberse agotado en una ocasión las existencias de este supercemento, se confeccionaron dos marcos con un cemento Portland normal, según el Pliego español, y sin ninguna característica especial.

\subsubsection{Arena}

En la confección del mortero se usó arena del Manzanares, pero no la monogranular, seleccionada, que se especifica en el Pliego, sino con finos y gruesos, tal como se extrae del río. No se tomó ninguna medida para calentar la arena, antes de emplearla. Tan sólo se tuvo, y no siempre, la precaución de preservarla de la intemperie, introduciéndola en la nave-taller el día anterior al de su utilización.

\subsubsection{Agua}

Tanto para los amasados como para obtener las disoluciones de cloruro cálcico se hizo uso, como en el caso de los ensayos de laboratorio, del agua potable de Madrid.

En algún ensayo se utilizó agua caliente, con objeto de sumar la acción de la temperatura a la propia del cloruro cálcico. No obstante, la temperatura del líquido de amasado no pasó de $35^{\circ} \mathrm{C}$ en ningún caso.

\subsubsection{Cloruro cálcico}

Fué de dos procedencias: uno, correspondiente al utilizado en los ensayos previos, con 3,5 moléculas de agua de cristalización; otro con 6 moléculas, y ambos en su calidad de productos puros.

Se calculó la riqueza aproximada en sal anhidra de cada uno, así como de las mezclas de ambos en distinta proporción, empleadas en la preparación de las disoluciones, y, finalmente, se fijó con exactitud la concentración de cada una de éstas, mediante determinación de su contenido de calcio. 
Para cada marco se tomó un volumen de disolución que contenía la cantidad de $\mathrm{CaCl}_{2}$ disuelto precisa, con arreglo al cemento previsto $-75 \mathrm{~kg}$ - para que la proporción en peso, con relación a éste, fuese siempre del $3 \%$.

Dicho volumen se diluyó, antes de añadirlo al resto de los materiales, hasta un volumen igual al de la totalidad del líquido de amasado, 25 litros.

\subsubsection{Armaduras}

Las armaduras se preparaban con anterioridad, atando convenientemente los hierros del cargadero a los estribos y colocándolas en el interior de los moldes, debidamente sujetas para mantenerlas en posición durante el llenado, vibrado y fraguado de la pieza. Los estribos equidistaban unos $12 \mathrm{~cm}$ y quedaban a muy escasa distancia de la pared del molde, es decir, muy próximos a la cara externa de la pieza. En las

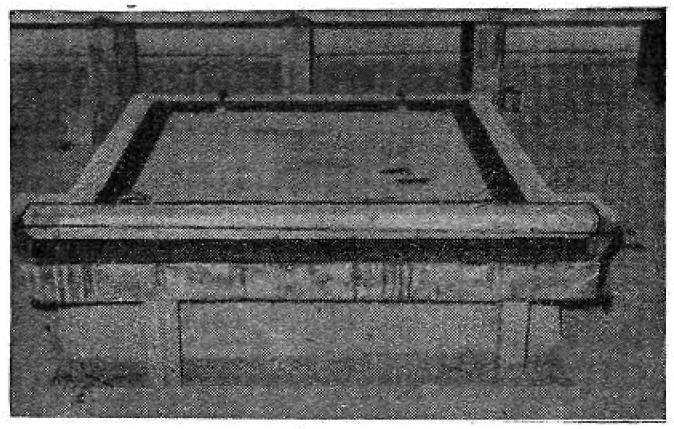

Fig. 16.-Molde listo para el Ilenado.

figuras 16 y 17 pueden observarse estos por menores, particularmente por lo que se refiere al cargadero.

\subsubsection{Los métodos}

Se exponen en lo que sigue los detalles de las distintas operaciones llevadas a cabo en la confección de los marcos.

\subsubsection{Amasado}

El amasado de la cantidad total de mortero necesario para cada marco se hizo de una sola vez y a mano, en una artesa. Se procedía primero a la mezcla en seco del cemento y la arena $y$, una vez logrado un conjunto suficientemente homogéneo, se añadía el líquido de amasado, continuando la operación hasta el final.

\subsubsection{Enmoldado y vibrado}

Los moldes, armados, de pasta pura de cemento o de mortero muy rico, y de superficies muy lisas, constaban de una parte fija al pavimento de la nave-taller y otras partes desmontables. Uno de ellos, montado y listo para su Ilenado, puede verse en la fig. 16.

Una' vez preparado el molde con la armadura en su interior, sujeta y en posición, y habiendo previamente impregnado sus paredes internas

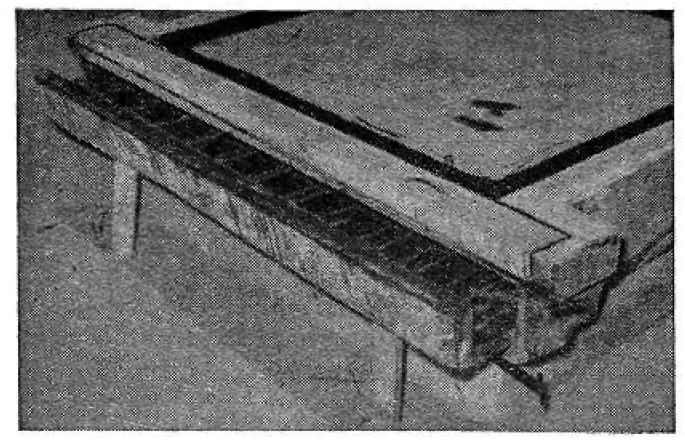

Fig. 17.- Molde con detalle de la armadura del cargadero. La separación de los estribos es de $12 \mathrm{~cm}$.

con una mezcla de estearina y gas-oil, que actúa de separador de encofrados y facilita el despegue de la pieza acabada, se procedía a su llenado con el mortero.

Se distribuía la masa por todo él $y$, a fin de hacer correr el mortero hacia el fondo y llenar bien todos los huecos, se utilizó un vibrador de aguja que se hacía actuar sobre la masa y sobre la armadura, con objeto de lograr una buena compacidad y reducir en lo posible el número y tamaño de las coqueras, cosa difícil en moldes 


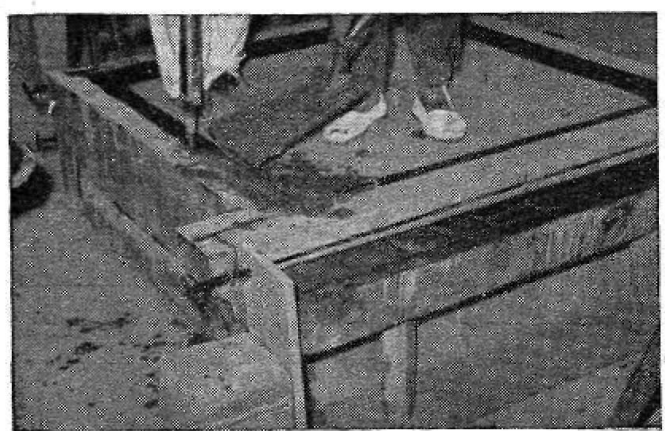

Fig. 18.-Operación de llenado de un molde.

estrechos y profundos. Detalles del llenado y vibrado quedan de manifiesto en las figuras 18 y 19.

\subsubsection{Curado}

La pieza, una vez enmoldada, se curaba en la nave-taller hasta que permitía efectuar cada una de las operaciones siguientes, que luego se detallan. No solamente no recibía calor externo alguno, sino que, además, la temperatura de la nave fué siempre baja.

Se registró mediante un termógrafo, a lo largo de toda una semana del mes de noviembre en que se realizaron los ensayos, y la gráfica obtenida es la de la figura 20 . Como puede apreciarse, la temperatura fué de $10 \pm 1,5^{\circ} \mathrm{C}$.

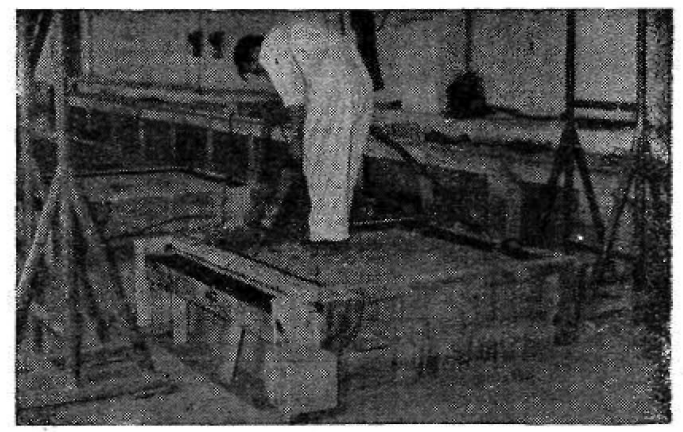

Fig. 19.-Vibrado de la masa con vibrador de aguja.

\subsubsection{Operaciones complementarias}

Al cabo de un cierto tiempo de curado, y cuando el aspecto de la masa lo permitía, se procedía al repaso y alisado de las caras libres de la pieza. Esto había de hacerse con la masa en fraguado avanzado, pero no concluído (43).

Posteriormente, y ya más adelantado el curado, se separaban los costeros de los moldes, quedando la pieza con las caras externas al aire, lo que facilitaba su secado, y las interiores todavía apoyadas y en contacto con la parte central e interna del molde, fija al pavimento de la nave, tal como se aprecia en las figuras 21 y 22.

Finalmente, cuando la pieza estaba suficientemente curada, se separaba del resto del molde, elevándola mediante una diferencial y un bas-

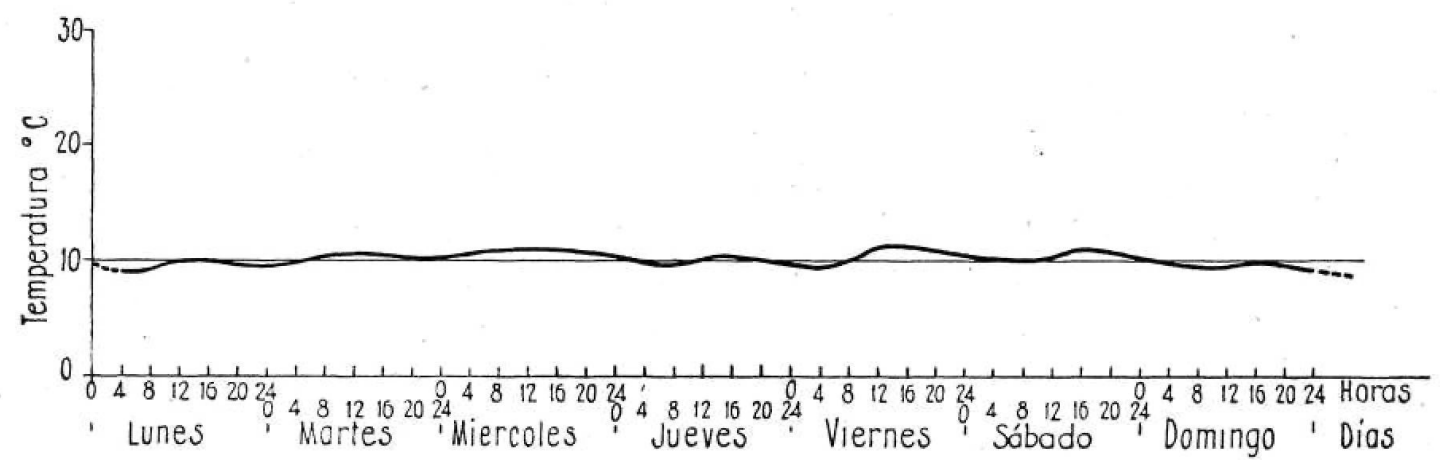

Fig. 20.-Curso semanal de la temperatura en la nave de prefabricación. 


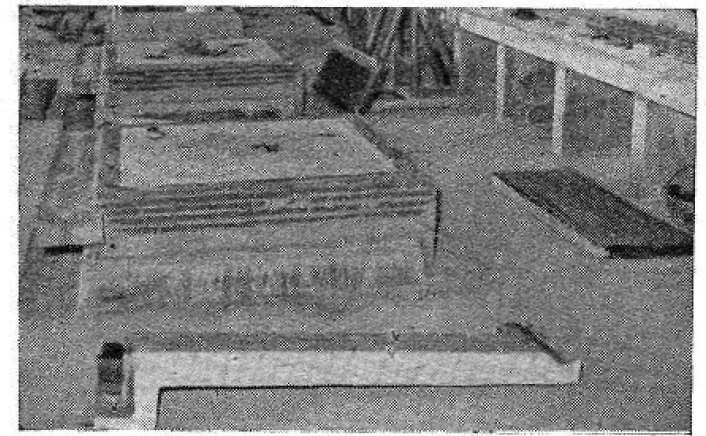

Fig. 21.-Separación de los costeros de los moldes

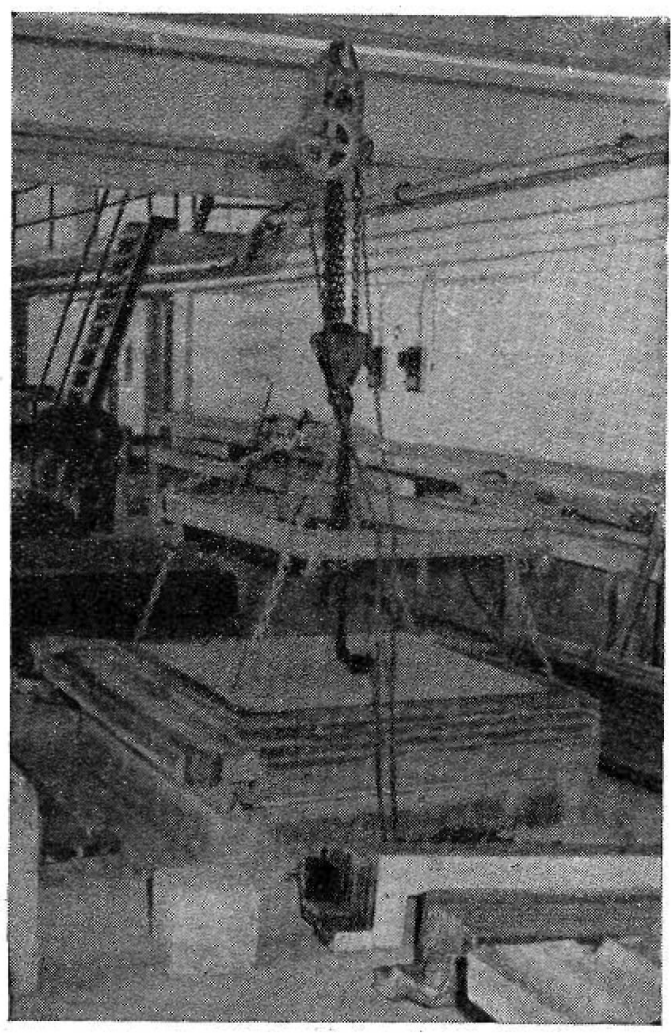

Fig. 23.-A Aarejo para el arranque de la pieza.

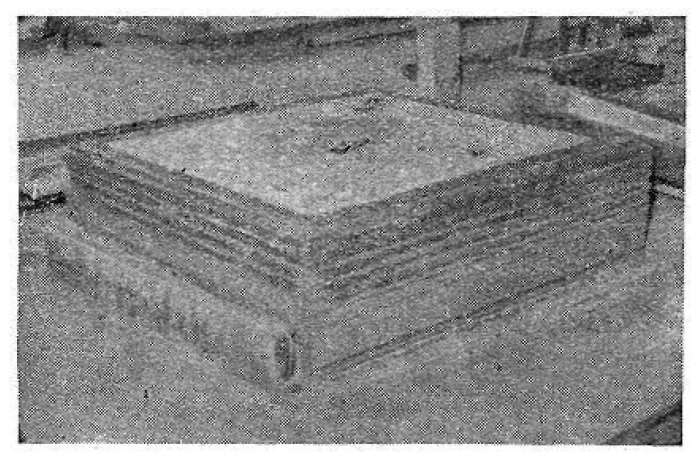

Fig. 22.-Pieza lista para el desmolcato final.

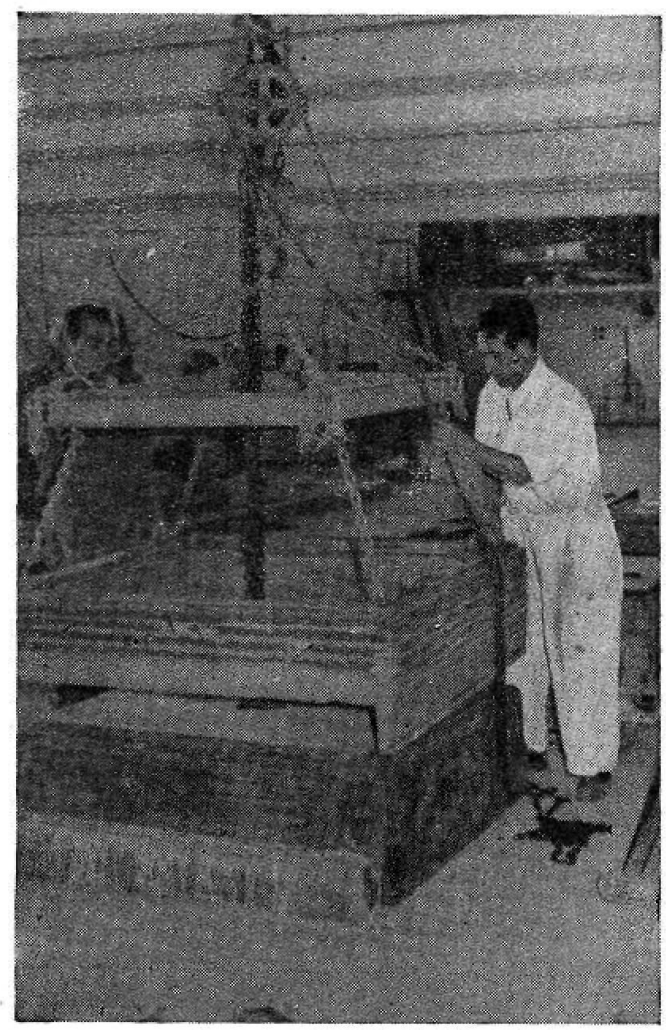

Fig. 24.-La pieza totalmente separada del molde. 
tidor cuadrado, con cuatro cadenas que se fijaban a otros tantos ganchos dejados a tal efecto en los cuatro vértices de la pieza (figs. 23 y 24).

Una vez depositadas las piezas en la parte de la nave dedicada a almacén, se procedía a la operación del kempolvado», consistente en rellenar con pasta pura de cemento las coqueras que se hubieran formado, y repasar algún desperfecto ocasional de las piezas.

\subsubsection{Los resultados}

Por lo que se refiere al fraguado, se observó, con el empleo de cloruro cálcico en la dosis de $3 \%$ de sal anhidra respecto del peso del cemento, una aceleración notable, de acuerdo con los resultados de los ensayos previos de laboratorio.

Cuando por falta de supercemento se utiJizó un cemento portland normal, los resultados fueron análogos a los observados con el supercemento, salvo, claro está, la mayor seguridad que da el trabajar con éste que, en cualesquiera circunstancias, proporciona mejores resistencias que aquél.

El calentamiento previo del líquido de amasado contrlbuye a favorecer la aceleración de! fraguado.

El cloruro cálcico en el agua de amasado hace que, para una relación agua/cemento dada, el mortero sea más flúido, lo cual significa que, para un grado de fluidez dado, es posible reducir la cantidad de agua de amasado empleando cloruro cálcico. La reducción del agua de amasado tiene un límite en este caso, puesto que, si se fuerza, el mortero no «corre» con facilidad, ni siquiera con la ayuda del vibrador $y$, sobre emplearse demasiado tiempo en la operación de llenado de los moldes, el número y tamaño de las coqueras crece considerablemente. Con todo, se consiguió rebajar la relación agua/cemento de 0,4 a 0,33 , empleando $3 \%$ de $\mathrm{CaCl}_{2}$ como adición.

Al reseñar los resultados obtenidos en la prefabricación de los marcos de ventana, utilizando cloruro cálcico como acelerador, se establece una comparación de tiempos, en relación con el procedimiento normal en que no se recurre al empleo de dicho producto, es decir, tal como se solia hacer ordinarlamente.

La comparación queda de manifiesto en el cuadro 12.
CUADRO 12

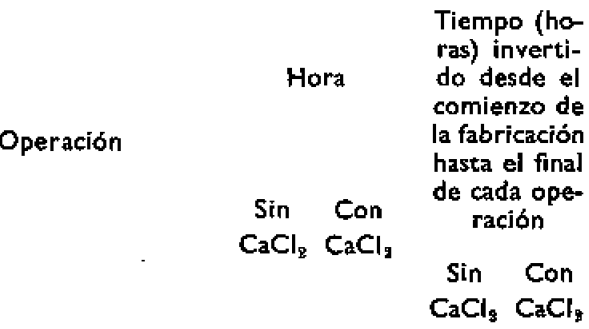

\begin{tabular}{|c|c|c|c|c|}
\hline $\begin{array}{c}\text { Amasado (comien- } \\
\text { zo) } \ldots \ldots \ldots \ldots\end{array}$ & $9^{\circ 0}$ & $9^{00}$ & - & - \\
\hline Enmoldado (fin) .. & $10^{\circ 0}$ & $10^{\infty 0}$ & ! & 1 \\
\hline $\begin{array}{c}\text { Repaso y alisado de } \\
\text { las caras ....... }\end{array}$ & $17^{\circ 0}$ & $12^{00}$ & 8 & 3 \\
\hline $\begin{array}{l}\text { Separación del en- } \\
\text { cofrado } \ldots . . .\end{array}$ & $9^{00 *}$ & $14^{\circ 0}$ & 24 & 5 \\
\hline $\begin{array}{r}\text { Extracción de la } \\
\text { pieza ......... }\end{array}$ & $9^{00 * *}$ & $17^{\circ 0}$ & 48 & 8 \\
\hline
\end{tabular}

Los resultados ponen de manifiesto que, mediante el empleo del cloruro cáleico en la dosis indicada, es posible reducir el tiempo de confección de cada pieza a 1/6 del normalmente requerido en el caso de no utilizar ninguna adlción aceleradora y ningún método físico de activación del proceso.

La consecuencia es que, en tales condiciones, para una producción dada es posible reducir en igual medida, bien el número de moldes necesarios $y$, por consiguiente, el espacio de taller. bien el tiempo $y$, en consecuencia, el gasto de mano de obra. En todo caso se reduce también el tlempo de almacenaje $y$ el espacio requerido para el mismo, con una producción dada, hasta la puesta en servicio de las piezas. La repercusión económica es, pues, extraordinaria.

\subsubsection{Retracción}

Los marcos confeccionados con la dosis de $3 \%$ de $\mathrm{CaCl}_{2}$ con relación al peso de cemento no presentarón en el plazo de un año el cuarteamiento $y$ las grietas típicas de retracción. 
Estas se presentan, sin embargo, en todos los marcos fabricados sin empleo de adición, ya a los 20 ó 30 días, particularmente en el alféizar, aunque también en las jambas y en el dintel. En este caso las grietas y el cuarteamiento aparecían aun en piezas que, a partir de su separación del molde, se mantuvieron sumergidas en agua durante dos, tres y cuatro días.

El cloruro cálcico parece, por tanto, ser la causa de la no aparición de las grietas de retracción, dado su papel en el curado, debido a su higroscopicidad y a la acción química que evidentemente ejerce sobre el fraguado $y$ en las reacciones de hidratación y endurecimiento del cemento.

Todo lo cual está de acuerdo con los resultados experimentales expuestos en 2.1.3.4. y

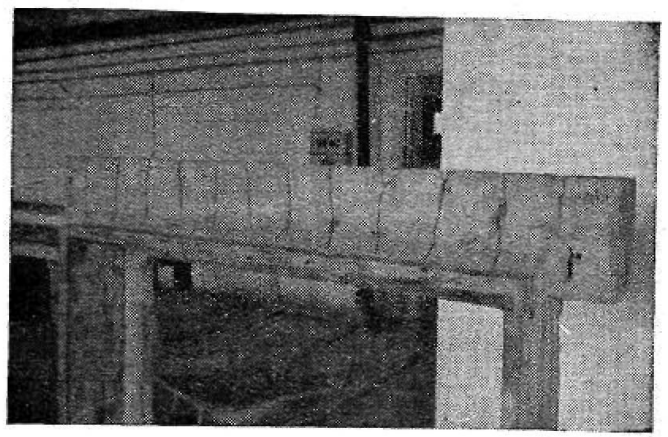

Fig. 25.-Detalle de un cargadero con grietas de expansión debidas a productos de corrosión de los estribos de la armadura.

con lo que afirma una parte, al menos, de los investigadores que se han ocupado del tema de la influencia del cloruro cálcico en las variaciones de volumen del cemento (véase I.3).

\subsubsection{Corrosión de armaduras}

En los cargaderos de las ventanas confeccionadas con cloruro cálcico aparecen, generalmente en todo su contorno, grietas espaciadas unas de otras unos $12 \mathrm{~cm}$, tal como se ha hecho destacar en las figuras 25,26 y 27. Esta distancia coincide con la de separación de los estribos de la armadura, los cuales quedan muy próximos a las caras externas de los cargaderos.

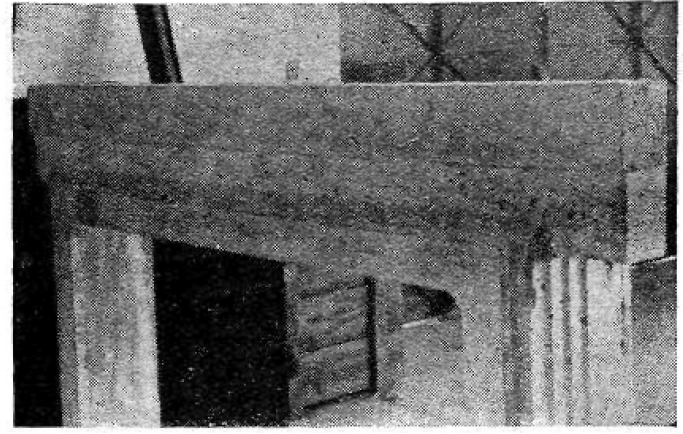

Fig. 26.-Parte posterior de un cargadero con las grietas de expansión por corrosión.

Estas grietas se producen por expansión y son debidas a corrosión de las armaduras, ya que los productos de la misma afloran a la superficie del hormigón dando lugar a manchas pardo-rojizas de óxidos y sales férricas que en las figuras citadas están señaladas con cruces.

Los productos secundarios de la corrosión del hierro por cloruros en un medio alcalino, como es el cemento, (óxidos de hierro más o menos hidratados), se forman con un considerable aumento de volumen a partir de los productos anhidros, lo cual da lugar a la expansión

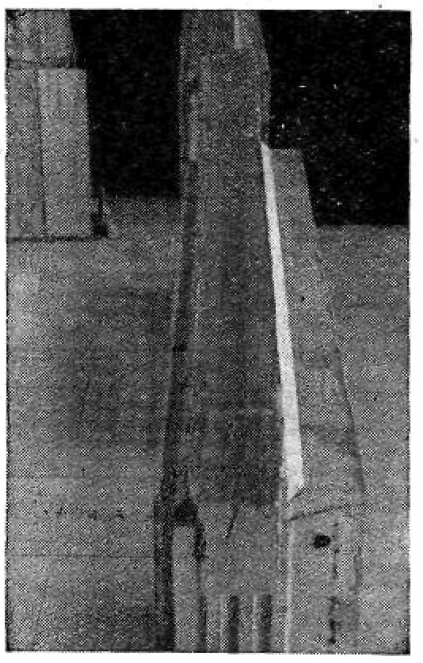

Fig. 27.-Parte superior de un cargadero en que se aprecian las grietas. 
y al agrietamiento, contribuyendo al mismo tiempo a disminuir la adherencla entre las armaduras y el hormigón $y$, en último extremo, al despegue de éstas.

En efecto, al deshacer dos de los citados cargaderos se observó que la armadura, y en particular los estribos, se hallaban recubiertos de productos de corrosión que habian producido un despegue parcial y la aparición de las grietas que se observan en las fotografías expuestas.

\section{DISCUSION DE LOS RESULTADOS $Y$ CONCLUSIONES}

Tanto de los resultados de los ensayos de laboratorio como de los de las experiencias de taller, se deduce que en el empleo del cloruro cálcico como acelerador del fraguado y endurecimiento del cemento portland existe una dosis que produce óptimos efectos. Por debajo de un cierto valor, el cloruro cálcico retarda los procesos.

En nuestro caso, la dosis óptima es la correspondiente a un $3 \%$ de sal anhidra $\mathrm{CaCl}_{2}$ con ręlación al peso del cemento, aproximadamente. Podría decirse, más bien, que está comprendida entre 2,5 y 3,5, dependiendo el desplazamiento hacia uno u otro de dichós valores extremos de que se consideren preferentemente la máxima aceleración de fraguado, las resistencias a muy corto o largo plazo, las de compresión o las de tracción. Como quedó indicado en I.3, otros investigadores encontraron valores algo distintos.

Al tratar de hallar una explicación racional de nuestros resultados, así como de las diferencias con los de otros autores, se acude en primer lugar, a los conocimientos, válidos hasta el presente, acerça de la acción química del cloruro cálcico sobre el cemento.

Sentado que en la reacción del cloruro cálcico con el aluminato tricálcico de aquél, se forma un cloroaluminato complejo, semejante a los conocidos sulfoaluminatos (véase 1.3 ), se admite que a dicho cloroaluminato le corresponde la fórmula hallada por Friedel (35):

$$
3 \mathrm{CaO} \cdot \mathrm{Al}_{2} \mathrm{O}_{3} \cdot \mathrm{CaCl}_{2} \cdot 10 \mathrm{H}_{2} \mathrm{O}
$$

Es problemático que esta sal de lugar a disoluciones sólidas con los aluminatos hidratados.
Los aluminatos reaccionan normalmente con el yeso para formar el sulfoaluminato monosulfato de fórmula $3 \mathrm{CaO} . \mathrm{Al}_{2} \mathrm{O}_{3}, \mathrm{CaSO}_{4} \cdot 10 \mathrm{H}_{2} \mathrm{O}^{\text {(58) (59). }}$ Según esto, cada mol de $\mathrm{SO}_{3}$ fija un mol de aluminato en forma compleja, $y$, puesto que el contenido de $\mathrm{SO}_{3}$ del cemento estudiado es de $2,19 \%$ (véase cuadro 2), la cantidad de aluminato fijada es de $7,39 \%$. Como el total de aluminato tricálcico encontrado por el cálculo potencial es de $14,70 \%$ (véase cuadro 3 ), el resto, $7,31 \%$ queda libre para dar lugar, con el cloruro cálcico, a la sal de Friedel. Para ello es es tequiométricamente precisa una cantidad de cloruro cálcico anhidro del $3,005 \%$.

He aquí una posible explicación de por qué, en nuestro caso, la mayor aceleración del fraguado y las mejores resistencias mecánicas a corto plazo se consiguen con una dosis de cloruro cálcico anhidro equivalente o muy próxima al $3 \%$ del peso del cemento.

Según esto, la cantidad óptima de $\mathrm{CaCl}_{2}$ en cada caso dependerá, fundamentalmente, de dos factores: el contenido de aluminato tricálcico del cemento y el contenido de yeso $\left(\mathrm{SO}_{3}\right)$ añadido al elf́nker de procedencia, para regular el fraguado.

La cifra media de aluminato tricálcico en los cementos españoles es, aproximadamente, de $14 \%$ y el máximo porcentaje de $\mathrm{SO}_{3}$ permitido por el Pliego (83), de $2,5 \%$. A este porcentaje corresponde, para formar sulfoaluminato monosulfato, un $8,44 \%$ de aluminato tricálcico. Queda, pues, por término medio, un $5,56 \%$ de $C_{3} A$ para reaccionar con, un $2,28 \%$ de $\mathrm{CaCl}_{2}$. Puede decirse que, en general, la cantidad óptima de cloruro cálcico anhidro a añadir a los cementos españoles está por encima de dicho valor.

Los cementos norteamericanos tipo III, que son los más parecidos a los españoles por su riqueza en aluminato tricálcico, contienen, como máximo, $15 \%$ de $\mathrm{C}_{\mathrm{g}} \mathrm{A}$ y $3 \%$ de $\mathrm{SO}_{3}$. A $3 \%$ de $\mathrm{SO}_{3}$ corresponde $10,13 \%$ de $\mathrm{C}_{3} \mathrm{~A}$ para formar el sulfoaluminato monosulfato, quedando como máximo $4,87 \%$ de $\mathrm{C}_{3} \mathrm{~A}$ para convertirse en cloroaluminato, lo que exige $2 \%$ de $\mathrm{CaCl}_{2}$, o sea $2.5 \%$ del producto comercial con riqueza de $78,5 \%$. En general, considerando como cifras medias de $\mathrm{C}_{3} \mathrm{~A}$ y $\mathrm{SO}_{3} 12,5 \%$ y $2,5 \%$ respectivamente, resulta para el cloroaluminato un $1,67 \%$ de $\mathrm{CaCl}_{2}$, que equivale, aproximadamente, al $2 \%$ del producto comercial de $77-80 \%$ de riqueza en sal anhidra. Esto está de acuerdo con la mayoría de los resultados experimentales reseñados en trabajos norteamericanos. 
De aquí que, por lo regular, los valores óptimos de cloruro cálcico a añadir a los cementos oscile entre el 1,5 y el $3,5 \%$ del producto puro anhidro, o entre el $2 \cdot y$ el $4 \%$ del producto comercial, como se indicó en l.3.

Resumiendo estas ideas podria decirse que, de la misma manera que se introdujo el concepto de cemento «correctamente retardado» $(59)$, entendiéndose por tal aquél cuyo contenido de $\mathrm{SO}_{\mathrm{g}}$ es el preciso para hacer desaparecer la tercera fase de la hidratación del mismo, es decir, la de los aluminatos residuales, después de la transformación cuantitativa del yeso en sulfoalumirato, podría definirse como cemento «correctamente adicionado de cloruro cálcico» aquél cuyo contenido de dicha sal fuese el necesario para convertir en cloroaluminato el aluminato cálcico restante, después de haber șido fijado como sulfoaluminato monosulfato todo el $\mathrm{SO}_{\mathrm{g}}$ disponible. En definitiva, la suma de $\mathrm{SO}_{3} \mathrm{y}$ $\mathrm{CaCl}_{\text {g }}$ deberia ser tal que entre los dos consumiesen la totalidad del aluminato para formar $\mathrm{C}_{8} \mathrm{~A} . \mathrm{CaSO}_{4}$. 10-12 $\mathrm{H}_{2} \mathrm{O}$ y $\mathrm{C}_{3} \mathrm{~A} . \mathrm{CaCl}_{8}$. $10 \mathrm{H}_{2} \mathrm{O}$, respectivamente.

Con esto quedaría cuantitativamente explicada la dependencia entre el $\mathrm{CaCl}_{2}$ óptimo $y$ los contenidos de $\mathrm{C}_{3} \mathrm{~A}$ y $\mathrm{SO}_{3}$ de cada cemento.

La analogía setía aún mayor, ya que el $\mathrm{SO}_{3}$ correspondiente a un cemento «correctamente retardado» coincide también con el porcentaje de $\mathrm{SO}_{3}$ 《óptimo» (i刃) (59).

En cuanto al problema de la retracción, es difícil enjuiciar los hechos observados, a la luz de los resultados de otros investigadores, pues ya se indicó que las opiniones ac erca de esta cuestión han estado siempre, y siguen estando, muy divididas (véase I.3). En las condiciones experimentales en que se ha trabajado, parece, no obstante, que a partir de las 72 horas de su confección, las probetas con un $3 \%$ de cloruro cálcico experimentan una expansión que llega a anular e incluso desbordar los efectos de la retracción. Una vez estabilizada y compensada en parte por la retracción, la expansión resultante es menor que la retracción que a las mismas edades se observa, en el caso de no emplear el cloruro cálcico. Esto parece indicar que en las condiciones en que se realizaron los ensayos descritos en 2.1.3.4., es decir, en ambiente húmedo a saturación, con alguna dosis menor de cloruro cálcico, comprendida entre el $3 \%$ estudiado $y$ el $1,6 \%$ más generalmente empleado (correspondiente al $2 \%$ del producto comercial, según el cuadro 4), sería tal vez posible compensar
Ja retracción, sin tener una expansión adiçional. $O$, también, con la dosis del $3 \%$ en un ambiente de conservación más seco. Todo ello estaría de acuerdo con alguno de los puntos de vista expuestos en I.3.

También parece abonar esta idea el hecho de que el $C_{g}$ A potencial (36) (46) (53) y los altos valores del módulo alumínico (relación $\mathrm{Al}_{2} \mathrm{O}_{3} / \mathrm{Fe}_{2} \mathrm{O}_{3}$ ) de un cemento (46) favorecen la retracción. La eliminación total de ésta sólo sería posible mediante la adición al cemento de un agente expansivo que se opusiera a ella y produjese en cada momento una expansión jgual a la retracción normal en cada instante (54).

De la misma manera que se ha pensado en utilizar para tal fin la sal de Candlot (54)(62), y que se ha visto que cantidades de $\mathrm{SO}_{3}$ superiores a las especificadas en las Normas (98), -precisamente del orden de la necesaria para transformar en sulfoaluminato monosulfato todo el $\mathrm{C}_{3} \mathrm{~A}$ del cemento- reducen considerablemente o hacen desaparecer la retracción (17), puede pensarse también que la sal de Friedel cumple el mismo cometido.

$Y$, de ser así, vuelve a darse otra vez la analogía entre el contenido de $\mathrm{SO}_{\beta}$ «óptimo» o necesario para un cemento «correctamente retardado» y el cloruro cálcico «óptimo» o correspondiente a una dosificación «correcta» del mismo. Es decir, la suma de porcentajes de $\mathrm{SO}_{3}$ y de $\mathrm{CaCl}_{2}$ en el cemento debe ser tal, que resulte suficiente para transformar todo el $C_{3} A$ en $\mathrm{C}_{3} \mathrm{~A} . \mathrm{CaSO}_{4} \cdot 10-12 \mathrm{H}_{2} \mathrm{O} \circ \mathrm{C}_{3} \mathrm{~A} . \mathrm{CaCl}_{2} \cdot 10$ $\mathrm{H}_{2} \mathrm{O}$, o, en mezcla de ambos.

Todo esto va de acuerdo con los resultados experimentales expuestos en 2.1.3.4. y explica claramente por qué se observa una notable mejoría en el aspecto de las grietas y del cuarteamiento debido a la retracción en los marcos confeccionados con cloruro cálcico, con relación a los que no contienen dicha adición, según consta en 2.2.4.1.

En cuanto a las grietas que aparecen en los marcos no tratados, pueden ser debidas a los siguientes hechos: el cemento empleado es un supercemento, y, como tal, posee una gran finura que se revela en los escasos residuos sobre los tamices y en la elevada cifra de superficie específica. Esto hace que la cantidad de agua para el amasado del mortero sea grande, como refieja el porcentaje de agua preciso para confeccionar la pasta de consistencia normal (véase 2. I. I.2.). Tamblén la gran superficie específica. hace que la cantidad de aluminatos disponibles 
para entrar inmedlatamente en reacción con el agua sea mayor (59), y tanto más cuanto que el contenldo de $C_{g} A$ del cemento empleado es elevado (cuadro 3). Por otra parte, la relación cemento/arena es alta, como corresponde a un mortero muy rico en cemento, y sabido es que la retracción es mayor en pasta pura que en mortero, $y$ en éste que en hormigón. Todas ellas son circunstancias que, evidentemente, favorecen la retracción. Hay, por añadidura, otro hecho bien conocido que pudiera explicar la gran retracción de los marcos no tratados, y es que los resultados de las medidas y los efectos de la retracción dependen en gran manera de la geometría (forma y dimensiones) de la probeta o pieza que se estudia, $Y_{a}$ queda expuesto en 2.2.1. que los marcos con que se ha trabajado son piezas de masas desigualmente repartidas, muy grandes y con cantos de poco espesor, factores todos que, unidos a los anteriores, hacen más fácil cualquier manifestación externa de los fenómenos de retracción. Lo que, una vez más, confirma los satisfactorios resultados conseguidos con el empleo del cloruro cálcico.

En cuanto a los fenómenos de corrosión observados en las armaduras, y de los cuales es causa directa la presencia del cloruro cálcico, no cabe duda de que en ellos juega un importante papel el escaso espesor de hormigón que cubre a los estribos. En tales condiciones, la más ligera falta de compacidad hace llegar a la armadura aire y humedad exteriores, produciéndose el ataque y la formación de sales de hierro (cloruros), que, en el medio alcalino del cemento fraguado y húmedo, se transforman en oxihidróxidos en mezcla, con un mayor o menor grado de oxidación e hidratación.

Estos productos son de naturaleza esponjosa $y$, por tanto, porosos, por lo que, al no cubrir completamente la superficie del metal, dejan acceso a la misma al aire y a la humedad $y$, en consecuencia, no confieren una protección adecuada a la armadura.

Son además, muy voluminosos, y su formación tiene carácter expansivo, por lo cual, en la interfase entre la armadura y el hormigón se desarrollan fuertes tensiones que provocan el despegue e incluso el agrietamiento, con aparición de fisuras externas.

Si el hormigón o mortero es compacto y el espesor del recubrimiento es mayor, la corrosión no se produce, o sus efectos son muy tenues, aun con contenidos altós de cloruro cálcico, como confirma la experiencia de otros autores (véase 1.3.)
De cuanto antecede pueden extraerse las siguientes conclusiones:

1."-Debe existír una adiclón óptima de cloruro cálcico para cada cemento en función, principalmente, de sus contenidos de $\mathrm{C}_{\mathrm{g}} \mathrm{A}$ potencial $y$ de $\mathrm{SO}_{\mathfrak{y}}$.

2.-Esta adición óptima suele oscilar entre el $1,5 \%$ y el $3,5 \%$ de producto puro anhidro, o entre el $2 \%$ y el $4 \%$ del producto comercial hidratado, con una riqueza de 7 al $80 \%$ de sal anhidra, respecto del peso de cemento.

3.'-La adición óptima correspondiente a los cementos españoles suele ser alta, dado su elevado contenido de aluminato tricálcico. En ef caso estudiado en este trabajo fué del $3 \%$ de cloruro cálcico anhidro, equivalente a un $3,75 \%$ del producto comercial en escamas.

4. *-Este porcentaje óptimo reduce prácticamente a un minimo el tiempo de fraguado y eleva las resistencias mecánicas a tracción y compresión a todas las edades $y$. particularmence a las tempranas.

5."-Asimismo, el cloruro cálcico en la dosis utilizada evita en gran medida y puede decirse que casi en su totalidad, la aparición de cuarteamientos y grietas de retracción, como se deduce de las observaciones hechas al cabo de un año.

6." - Las grietas de retracción observadas en las plezas no confeccionadas con cloruro cálcico son atribuibles a la gran proporción de cemento en el mortero, a la gran finura del supercemento utilizado, a la relación agua/cemento un tanto elevada y a la forma y dimensiones de las piezas.

7."-Cuando las piezas armadas prefabricadas tienen las armaduras o los estribos de las mismas muy superficiales, como consecuencia de los pequeños cantos y espesores, es posible aparezcan fisuras per expansión debida a los productos de la corrosión que en tales condiciones tiene lugar, parcicularmente en el caso de emplear cloruro cálcico como acelerador. Al desarrolio de esta corrosión contribuye notablemente, además de la presencia del cloruro cálcico y de los débiles recubrimientos de las armaduras, la falta de compacidad debida a defectos de llenado y asentamiento de la masa de mortero u hormigón $y$, particularmente, a la aplicación de elevadas rẹlaciones agua/cemento.

8."-El empleo del cloruro cálcico en dosis de $3 \%$ de sal anhidra con relación al peso de cemento permite reducir a la sexta parte el tiempo necesario para la total confección de 
los marcos de ventana estudiados, to que supone una gran economía de moldes, mano de obra y tiempo, asi como un ahorro de espaclo de almacenaje, para una producción dada. Recíprocamente, con unos elementos determinados, la producción se puede sextuplicar.

\section{BIBLIOGRAFIA}

I. ABRAMS, D. A.: Proceedings A. S. T. M. 24/11, 781 (1924).

2. ANSTETT, M.: Pit and Quarry $|4,5|$ (I927).

3. A. S. T. M. Committee Reports $31 / 1,331$ (193I).

4. A. S. T. M. Standard Methods C230-52T, C204-55 y CI $51-54$.

5. A. S. T. M. Standard Methods C15I-54.

6. BAUER, E. E.: Proceedings A. C. I. 25 , 314 (1929).

7. BLAESE, O. VON: Tonindustrie Ztg. 30, 1734 (1906).

8. BOGUE, R. H.: Portland Cement Assoc. Fellowship, Paper No. 49 (1947).

9. BOGUE, R. H.: The Chemistry of Portland Cement. New York (1955).

10. BROCARD, J.: Ann. Inst. Téchn. Bât. Trav. Publics 9/103-104, 7/0 (1956).

II. BROCARD, J.: Surveyor, London Eng. 14 enero (1949).

12. BURCHARTZ, H.: Journal Soc Chem. Ind. 29, 108 (1910).

13: BURENIN, V. R.: Stroitelnaia Promuischlennost $n \cdot 9,36$ (1956).

54. BUTT, YY. M. y ROYAK, G. S.: Zhurnal Priklad Xim, 29, 7 (1956); Chimie Industrie 76, 1082 (1956).

15. CALLEJA, J.: «El cloruro cálcico en la Construcción». Manuales I. T. C. C. Madrid (1957).

16. CALLEJA, J.: XXVIII Congreso Internacional de Quimica Industrial. Madrid. (1955).
17. CALLEJA, ].: III Reunión Internacional sobre Reactividad de los Sólidos. Madrid (1956).

18. CANDLOT, E.: Journal Soc. Chem. Ind. 8, 543 (1889); Tonindustrie $\mathrm{Ztg} .13,345$ (1889).

19. CARPENTER. R. C.: Cement Age 2,207 (1906); Eng. News 53, 13 (1905).

20. Cement and Concrete Assoc. Library Record, Ch. 6 (10/51).

21. Cement, Lime and Gravel 30, 250 (1955).

22. Cemento Portland (Argentina) 34, 9 (1955).

23. Civil Eng. and Public Works Rev. 50, 515 (1955).

24. COCAGNE, J. y MATRAS, M. Y.: Rev. Mat. Const.' Trav. Publics, 32I-30 (1928); Chem. Abst. 23, 495 (1929).

25. CORNTHWEIT, C. R. Y YATES, J. C.: Proceedings $22^{\text {nd }}$ Annual Meeting Highway Res. Board (1942).

26. COTTRINGER y KENDALL: Concrete Mag. 4, 150 (1923).

27. CHAPMAN, H. P.: Highway Res. Abst. sept. (1932).

28. DAUTREBANDE, J.: Le Ciment 26, 291 (1921).

29. DURIEZ, M.: Rev. Mat. Const. nos 482-83, 110 (1955); Travaux, enero (1956).

30. DURIEZ, M.: Rev. Mat. Const. Trav. Publics. Ed. C. n. 449,45 (1953).

31. Engineering and Contracting 60, 202 (1923).

32. FERRARI, F.: Ceram. Abst. 3, 3II (1924).

33. FORSEN, L.: Proceedings Symp. Chemistry of Cements. Stockholm (1938).

34. FOSTER, B. E.: Journal A. C. I. 22/I, 32 (1950).

35. FRIEDEL, G.: Bull. Soc. Franç. Mineral 19, 122 (1897), en Kühl, H.: Zement-Chemie III, 93 ; 145 (1952).

36. GONNERMAN, $H, F_{*}$ : Proceedings A. S. T. M. 23, 318 (1923).

37. GRAF, O.: Zement 16/34, 776 (1927). 
38. GUINEA, S.: Comunicación privada (1955).

39. GUTTMANN, A.: Zement 9, 310; 429 (1920).

40. HEDIN, R.: Proceedings Svenska Cement och Betong Institutet 3 (1945).

41. HOGENTOGLER, C. A.: Proceedings loth Annual Meeting Highway Res. Board (1930).

42. HOGENTOGLER, C. A.: Proceedings I th Annual Meeting Highway Res. Board (1931).

43. HOWARD, E. L.: Journal A. C. I. $27 / 3,378$ (1955).

44. IVANOV, F. M.: Stroitelnaia Promuischlennost n." 9, 71,15 (1954).

45. KALOUSEK, G. L., JUMPER, C. H. y TREGONING, J. J.: Journal Res. Nat. Bureau Standards 30, RP 1530 (1943).

46. KALOUSEK, G. L.: Journal A. C. I. 26/3, 242 (1954).

47. KARTASOV, K. N.: Stroitelnaia Promuischlennost n. 12 (1957).

48. KILLIG, F.: Zement II, 487; 499; 507; 515 (1922).

49. KILLIG, F.: Zement Vol. 45 a 48 (1922); PLATZMANN, C. R.: Zement $\|$ (1922).

50. KIND, V. V., LAURINOVITCH, E. V. y LITVINOVA, R. E.: Tsement 2I/3, 7 (1955); Journal A. C. I. 28, 429 (1956).

5I. KRYLOV, B. A.: Stroitelnaia Promuischlennost $n .^{\circ}$ I, '33 (1957).

52. KUHL, H. y ULRICH, E.: Zement 14,859 ; 880; 898; 917 (1925).

53. KÜHL, H.: Zement-Chemie III, 304. Verlag Technik, Berlin (1952).

54. LAFUMA, H.: Proceedings Symp. Chemistry of Cements London (1952).

55. LANG, F. C. y BURGgRAFF, F.: Proceedings 9th Annual Meeting Highway Res. Board 9/1, 369 (1929).

56. LATISEV, I. N.: Stroitelnaia Promuischlennost n. 12 (1957).

57. Le Génie Civil, 349 (1935).
58. LEA, F. M. y LEE, C. R.: «Shrinkage and cracking of "cementive materials» Soc. Chem. Ind. London (1947).

59. LERCH; W.: Proceedings A. S. T. M. 46 (1946).

60. LEVENS, A. S.: Eng. News Record 99/23, 912 (1927).

61. LEVENS, A. S.: Eng. News Record 97/6, 215 (1926).

62. L+HERMITE, R.: Soc. Chem. Ind. London (1947).

63. LJANIN, N.: Tonindustrie Ztg. 26, 874 (1902).

64. MACCALL, J. T. y CLAUS, R. J.: Highway Res. Abst. 22, 33 (1952).

65. MATTIMORE, H. S. y MILLER, H. H.: Proceedings A. S. T. M. $31 / 1347$ (193I).

66. MATTIMORE, H. S.: Proceedings A. S. T. M. 23, 318 (1923).

67. MEADE, R. K.: Eng. Record, 20 abril (1907).

68. MELNIKOV, F. I.: Stroitelnaia Promuischlennost n.॰ I, 42 (1957).

69. MILLER, H. H. Proceedings 10 $0^{\text {th }}$ Annual Meeting Highway Res. Board, 403 (1930).

70. MILLER, H. H.: Proceedings $13^{\text {th }}$ Annual Meeting Highway Res. Board 12 (1933).

7I. MORAN, W. T.: Journal A. C. I. 26, I13 (1954).

72. MULlER, P. P.: Mag. Concrete Res. n.*6, 34 (1954).

73. NEWMAN, E. S., BLAINE, R. L., JUMPER, C. H. y KALOUSEK, G. L.: journal Res. Nat. Bureau Standards 30, RP 1533 (1943).

74. NEWMAN, A. J.: Concrete and Const. Eng. 159 (1943); Building Sc. Abst. 16, 1948 (1943).

75. OVCHAROV, V. I.: Stroitelnala Promuischlennost n.: I, 38 (1955).

76. PANFILOVA, L. I. Y KOZLOVA, G. A. Beton i Zhelezobeton $n .^{\circ} 1,33$ (1955); Highway Res. Abst. 26,5 (1956). 
77. PEARSON, J. C.: Proceedings A. S. T. M. 23,328 (1923).

78. PITT, W. J.: Chem. Eng. and Mining Rev. 5 nov. (1928).

79. PLATZMANN, C. R.: Zement II, I37; 157 (1922); Chimie et Industrie 8, 614 (1922); Chem. Abst. 16. 4318 (1922).

80. PLATZMANN, C. R.: Cemient and Cement Manuf. 2/3, 89 (1929); Butld. Sc. Abst. 23, 146 (1929).

81. PLATZMANN, C. R.; Rock Products 6 feb. (1926).

82. PLATZMANN, C. R.: Zement 10, 499 y 555 (1921); Chimie et Industrie 7,943 (1922); Chem. Abst. 16, 2386 (1922).

83. Pliego general de condiciones para la recepción de aglomerantes hidráulicos en obras de carácter oficlal, en: Curso Auxiliares Laboratorio, vol. III, I. T. C. C. (1954).

84. PRICE, W. H.: Journal A. C. I. $22 / 6,417$ (1951).

85. Proceedings $10^{\text {th }}$ Annual Meeting Highway Res. Board, dic. (1930).

86. RAPP. P.: Proceedings 13th Annual Meetings Highway Res. Board 29l (1933); id.

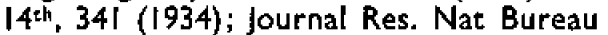
Standards 14,499 (1935) R. P. n. 782.

87. RATCH, E. G.: Stroitelnaia Promuischlennost $33 / 327$ (1955).

88. ROHLAND, P.: Ber. Deutsch. Chem. Ges. $33,2831(1901)$

89. ROHLAND, P.: Zeitschr. Angew. Chem. 16, 622; 1049 (1903); Zeitschr. Elektroch, $10,893,(1904)$.

90. ROHLAND, P.: Stahl und Eisen 28, I805 (1908); Journal Soc. Chem. Ind. 28, 23 (1909).

91. RUSSELL, H. W.: Roads and Streets, julio (I943).

92. SCHARROO, P. W. Cement (Holanda) 7,235 (1955); Journal A. C. 1. 29, 713 (1957).
93. SERV-SERVINA, N. N. y otros: Vestnik Akad. Nauk (S. S. S. R.) III/3, 659 (1956).

94. SHANK, J. R.: Chem. Abst. 33/2l, 8947 (1939).

95. SHIDELER, J. J., BREWER, H. W. Y CHAMBERLAIN, W. H.: Journal A. C. 1. 22/6 ([95I).

96. SHIDELER, J. J.: Journal A. C. I. $23 / 7,537$ (1952).

97. SHREVE, E. C.: Tesis doctoral. Universidad de Ohio (1929)

98. SIZOV. V. N.: Stroitelnaia Promuischlennost $33 / 9,30$ (1955).

99. SLOANE, R. C. MCCAUGHEY, W. J. FOSTER, W. D. y SHREVE, E. C.: Eng. Exper. Station Bull. n. 61 , Ohio University (193J).

100. STANTON. T. E.: Proceedings. 30th Annual Meeting Highway Res. Board (1950).

101. STANTON, T. E..: Journal A. C. I. Novlembre (1940).

102. STEWART, L. C.: Proceedings A. S. T. M. 26/II, 45I (1926).

103. SWALlOW, H. T. S.: Civil Eng. Sep. (1938).

104. THOMAS, W. N.: Dept. Sc. and Ind. Res. Bujlding Res. Special Report n. ${ }^{\circ}$ i4 London Eng. (1930).

105. ThuilleauX, M.: Rèv. Mat. Const. Trav. Publics, 228 (1938); 12; 37; 55; 76; 93; 116; 133 (1939); Chem. Abst. $34,4879(1940)$.

106. THUILlEAUX, M. : La Techn. Mod. Const. 5/3. 79 (1950).

107. TURRICIANI, R. y SCHIPPA, G.: Building Sc. Abst. 236 (I956).

108. UCHIDA, S.: Report of Sendai Higher Techn. School 4, marzo (1926).

109. UCHIDA, S.: Mem. Sendai Higher Techn. School 6, 38I (1928); Chem. Abst. 23, 3322 (1929). 
110. UCHIDA, S.: Ceramic Abst. [I/3, 14I (1928).

III. VOLLMER, H. C.: Trabajo no publicado (1945). Ref.: Bibliog. 13, Highway Res. Board, publ. $n \circ 217$.

112. VOLLMER, H. C.: Proceedings $27^{\text {th }}$ Annual Meeting Highway Res Board 189 (1947).
113. WELLS, L. S.: Journal Res. Nat. Bureau Standards, Res. Paper n.० 34 (1928).

114. YATES, J. C.: Proceedings 2/3t Annual Meeting Highway Res. Board 288, 294 (1941).

115. YOUNG, R. N.: U. S. Bureau of Standards, Techn. Paper n." 174 (1920). 